\title{
Structure and Thermodynamics of Silicon Oxycarbide Polymer-Derived Ceramics with and without Mixed-Bonding ${ }^{\dagger}$
}

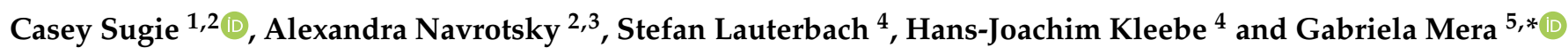 \\ 1 Department of Chemistry, University of California Davis, Davis, CA 95616, USA; csugie@ucdavis.edu \\ 2 Peter A. Rock Thermochemistry Laboratory and NEAT ORU, University of California Davis, \\ Davis, CA 95616, USA; Alexandra.Navrotsky@asu.edu \\ 3 Materials of the Universe, School of Molecular Sciences, Arizona State University, Tempe, AZ 851281, USA \\ 4 Institut für Angewandte Geowissenschaften, Technische Universität Darmstadt, Schnittspahnstraße 9, \\ D-64287 Darmstadt, Germany; stefan.lauterbach@geo.tu-darmstadt.de (S.L.); \\ kleebe@geo.tu-darmstadt.de (H.-J.K.) \\ 5 Institut für Materialwissenschaft, Technische Universität Darmstadt, Otto-Berndt-Straße 3, \\ D-64287 Darmstadt, Germany \\ * Correspondence: mera@materials.tu-darmstadt.de \\ † In Memoriam Prof. Masaki Narisawa who passed away on 27 January 2021.
}

Citation: Sugie, C.; Navrotsky, A.; Lauterbach, S.; Kleebe, H.-J.; Mera, G. Structure and Thermodynamics of Silicon Oxycarbide Polymer-Derived Ceramics with and without Mixed-Bonding. Materials 2021, 14, 4075. https://doi.org/10.3390/ ma14154075

Academic Editor: Lidong Chen

Received: 21 June 2021

Accepted: 19 July 2021

Published: 22 July 2021

Publisher's Note: MDPI stays neutral with regard to jurisdictional claims in published maps and institutional affiliations.

Copyright: (C) 2021 by the authors Licensee MDPI, Basel, Switzerland. This article is an open access article distributed under the terms and conditions of the Creative Commons Attribution (CC BY) license (https:// creativecommons.org/licenses/by/ $4.0 /)$.

\begin{abstract}
Silicon oxycarbides synthesized through a conventional polymeric route show characteristic nanodomains that consist of $\mathrm{sp}^{2}$ hybridized carbon, tetrahedrally coordinated $\mathrm{SiO}_{4}$, and tetrahedrally coordinated silicon with carbon substitution for oxygen, called "mixed bonds." Here we synthesize two preceramic polymers possessing both phenyl substituents as unique organic groups. In one precursor, the phenyl group is directly bonded to silicon, resulting in a SiOC polymer-derived ceramic (PDC) with mixed bonding. In the other precursor, the phenyl group is bonded to the silicon through Si-O-C bridges, which results in a SiOC PDC without mixed bonding. Radial breathing-like mode bands in the Raman spectra reveal that SiOC PDCs contain carbon nanoscrolls with spiral-like rolled-up geometry and open edges at the ends of their structure. Calorimetric measurements of the heat of dissolution in a molten salt solvent show that the SiOC PDCs with mixed bonding have negative enthalpies of formation with respect to crystalline components (silicon carbide, cristobalite, and graphite) and are more thermodynamically stable than those without. The heats of formation from crystalline $\mathrm{SiO}_{2}, \mathrm{SiC}$, and $\mathrm{C}$ of SiOC PDCs without mixed bonding are close to zero and depend on the pyrolysis temperature. Solid state MAS NMR confirms the presence or absence of mixed bonding and further shows that, without mixed bonding, terminal hydroxyls are bound to some of the Si-O tetrahedra. This study indicates that mixed bonding, along with additional factors, such as the presence of terminal hydroxyl groups, contributes to the thermodynamic stability of SiOC PDCs.
\end{abstract}

Keywords: silicon oxycarbide; polymer-derived ceramics; nanodomain structure; carbon nanorolls; polysiloxanes; energetics

\section{Introduction}

Silicon oxycarbide (SiOC) polymer derived ceramics (PDCs) are a class of advanced silica based ceramic materials that are synthesized through a polymeric route. PDCs have greatly impacted technological and scientific advances in ceramic materials1. They are able to resist crystallization, decomposition, phase separation and creep even at temperatures between 1000 and $1500{ }^{\circ} \mathrm{C}$ [1-3], have excellent mechanical properties [4], and are biocompatible and bioactive [5,6]. Silicon oxycarbide (SiOC) PDCs are commonly synthesized from precursors such as polysiloxanes and polysilsequioxanes [1,3,7-10]. SiOC PDCs are X-ray amorphous up to temperatures of approximately $1300^{\circ} \mathrm{C}$, making the structure and energetics of the disordered state very interesting. Despite being X-ray amorphous, PDCs contain distinct domains at the nanoscale, [11-14] making such microstructure largely 
responsible for thermodynamic and kinetic stability, properties that contribute to the materials' resistance to crystallization and oxidation [15].

The nanodomains most commonly consist of graphitic or turbostratic $\mathrm{sp}^{2}$ hybridized carbon, called 'free carbon', a region rich in silica, and some interfacial bonding region where mixed-bonding $\left(\mathrm{SiO}_{\mathrm{x}} \mathrm{C}_{4-\mathrm{x}}, 0 \leq \mathrm{x} \leq 4\right)$ is largely found. Solid state magic angle spinning nuclear magnetic resonance (MAS NMR) provides a powerful tool for determining local bonding and heterogeneity present at the nanoscale $[11,14,16]$. Information about the presence of mixed bonding $\left(\mathrm{SiO}_{x} \mathrm{C}_{4-\mathrm{x}}, 0 \leq \mathrm{x} \leq 4\right)$ that occurs at the interfacial region between the silica rich region and the "free carbon" region is gained from both ${ }^{13} \mathrm{C}$ and ${ }^{29}$ Si MAS NMR. Furthermore, Raman spectroscopy helps to identify the $\mathrm{sp}^{2}$ hybridized carbon species in the "free carbon" phase. The local nanostructural characteristics of PDCs are investigated by high-resolution transmission electron microscopy [7].

Understanding the thermodynamic stability of such SiOC PDCs, namely the enthalpy of formation from crystalline components, provides valuable information about the properties that make them promising materials for industry, specifically their stability at high temperatures. High temperature oxide melt solution calorimetry is a well-developed calorimetric technique [17-20] that has been used extensively for thermodynamic studies of PDCs $[7,12,13,15,21,22]$. Most of these calorimetric studies on SiOC PDCs have found that the enthalpy of formation from crystalline components is negative, meaning they are thermodynamically stable as compared to their crystalline components, with likely positive entropies of formation reflecting disorder and domain structure contributing to further stabilization. A look at their nanostructure provides some insight in the differences observed in their thermodynamic stabilities [1,7], which heavily rely on the compositional and structural make-up of the PDCs.

Moreover, there are reports showing that the interfaces between nanodomains may play an essential role in the thermodynamic stability of PDCs $[15,16]$. While there has been numerous research on the thermodynamic stability of SiOC PDCs with mixed bonding, only little is known about the thermodynamic stability of SiOC PDCs without mixed bonding. One study that investigated the thermodynamic stability of SiOC PDCs without mixed bonding showed that the enthalpy of formation from crystalline components was slightly negative [22]. A similar study involved two SiCN PDCs, with one that contained mixed bonding at the interface between nanodomains, while the other did not [16]. For the PDC without mixed bonding, the model suggests that there are two distinct phases, $\mathrm{Si}_{3} \mathrm{~N}_{4}$ and graphitic "free" carbon, with little to no Si-C bonds. While both samples revealed negative enthalpies of formation from crystalline components, the sample with interfacial bonding was significantly more thermodynamically stable (higher negative enthalpies). In addition, there seems to be a relationship to the hydrogen content of the material, being higher in the sample with interfacial bonding. It was concluded that hydrogen may also contribute to the thermodynamic stability of PDCs.

SiOC PDCs are synthesized by pyrolyzing polysiloxanes and polysilsequioxanes in an inert environment. While the resulting ceramic is $\mathrm{X}$-ray amorphous and has no long-range order, short-range order is present in the form of localized nanodomains. This short-range structure is made up of a continuous mass fractal network of corner shared $\mathrm{SiO}_{\mathrm{x}} \mathrm{C}_{4-\mathrm{x}}$ tetrahedra with some combination of $\mathrm{SiO}_{4}, \mathrm{SiO}_{3} \mathrm{C}, \mathrm{SiO}_{2} \mathrm{C}_{2}, \mathrm{SiOC}_{3}$, and $\mathrm{SiC}_{4}$ tetrahedral units [11], termed mixed-bonding. Voids within this network hold $\mathrm{sp}^{2}$ hybridized "free" carbon. When pyrolysis of polysiloxanes takes place in a $\mathrm{CO}_{2}$ environment, the microstructure differs in that it no longer contains mixed-bonding, but becomes a nanocomposite of silica and $\mathrm{sp}^{2}$ carbon $[23,24]$. Designing a polymer with sol-gel synthesis that has no Si-C bonds, but does contain carbon groups bonded to the $\mathrm{Si}$ through $\mathrm{Si}-\mathrm{O}-\mathrm{C}$ bridges also results in a ceramic with no mixed-bonding [22]. In this case, the carbon phase was observed as multiwall carbon nanotube-like $\mathrm{sp}^{2}$ hybridized carbon within a porous silica network, in-situ formed during pyrolysis without the need for any metal catalyst.

This study focuses on two different SiOC ceramics, one of which contains mixed bonding, while the other does not. Both SiOCs were synthesized using the sol-gel route at 
room temperature in water, which is advantageous as there is no requirement for synthesis in an inert environment and the final structure is solely determined by the bonding situation in the preceramic polymer.

Herein, NMR is used to determine the types of bonding present within the structure, FTIR to further confirm these bondings. Raman spectroscopy is employed for the characterization of the carbon phase and high-resolution TEM to determine the micro/nanostructure of the different SiOC samples. High temperature oxide melt solution calorimetry is used to determine the energetics and stabilities of the systems investigated. Such a combination of complementary techniques provides information as to how mixed bonding may contribute to the thermodynamic stability of SiOC PDCs and, in addition, offers indications about the role that hydrogen plays in this game.

\section{Experimental Procedures}

Synthesis: All chemicals were obtained and used as received from Sigma-Aldrich. Hydroquinone (HQ) $\geq 99 \%$, tetramethylorthosilicate (TMOS), trimethoxyphenylsilane (TMOPS) 97\%, and methanol were obtained from Sigma-Aldrich and used as received. The phenyl containing single-source non-mixed bonding precursors was prepared using $0.1,4$, and $8 \mathrm{wt} \%$ of HQ with respect to TMOS. The sol was prepared by adding water and TMOS to a mixture of methanol and HQ. The phenyl containing single-source mixed bonding precursor was prepared by adding water to a mixture of methanol and TMOPS. Ammonia was added dropwise to each reaction to obtain a $\mathrm{pH}$ of 9 . The gelation process was done at $60{ }^{\circ} \mathrm{C}$ and the wet gel was further allowed to age in a $60{ }^{\circ} \mathrm{C}$ drying cabinet for 5 days. The resulting xerogels (HQ0.1_SG, HQ4_SG, HQ8_SG, $\mathrm{PhSiO}_{1.5}$ SG) were dried in a $120^{\circ} \mathrm{C}$ drying oven for 5 days. Pyrolysis of each polymer was performed both at $800{ }^{\circ} \mathrm{C}$ and $1100{ }^{\circ} \mathrm{C}$ under an argon atmosphere $\left(100{ }^{\circ} \mathrm{C} / \mathrm{h}\right.$ heating rate, $2 \mathrm{~h}$ dwell time $)$.

Characterization: Powder X-ray diffraction measurements were performed on a Bruker D2 Phaser diffractometer (accelerating voltage: $30 \mathrm{kV}$, emission current: $10 \mathrm{~mA}$ ) operating in a Bragg-Brentano reflection geometry with a $\mathrm{Cu} \mathrm{K} \alpha$ radiation source $(\lambda=1.54185 \AA)$ and SSD160 1D detector. Data collection was conducted in the $2 \theta$ range of 5 to 120 degrees at a step size of 0.02 . FTIR spectroscopy was run on a Varian 670 spectrometer. The powdered sample was pressed in a KBr pellet. Each spectrum consists of 32 scans and was recorded with a resolution of $4 \mathrm{~cm}^{-1}$. Raman spectroscopy was conducted using a Horiba HR800 micro-Raman spectrometer equipped with an $\mathrm{Ar}^{+} 514.5 \mathrm{~nm}$ laser. The measurements were performed with a grating of $600 \mathrm{~g} / \mathrm{mm}$ and a confocal microscope at $50 \times \mathrm{g}$ magnification with a $100 \mu \mathrm{m}$ aperture. Neutral density filters attenuated the laser power on the samples in the range of $2 \mathrm{~mW}$ to $2 \mu \mathrm{W}$.

${ }^{29} \mathrm{Si}$ magic angle spinning nuclear magnetic resonance (MAS NMR) and ${ }^{13} \mathrm{C}\left({ }^{1} \mathrm{H}\right)$ crosspolarization (CP) MAS NMR spectra were collected using a $7 \mathrm{~mm}$ Bruker MAS probe and a Bruker Avance solid-state spectrometer operating at a Larmor frequency of $99.3 \mathrm{MHz}$ for ${ }^{29} \mathrm{Si}$ and $125.8 \mathrm{MHz}$ for ${ }^{13} \mathrm{C}$. Powdered samples were packed in $7 \mathrm{~mm} \mathrm{ZrO}_{2}$ rotors and spun at a rate of $7 \mathrm{kHz} .{ }^{29} \mathrm{Si}$ single-pulse MAS spectra of all samples were collected using a $60^{\circ}$ radio frequency pulse length of $2.6 \mu$ s and a 60 s recycle delay. Approximately 1500 free induction decays were collected and averaged for each ${ }^{29} \mathrm{Si}$ MAS NMR spectrum. ${ }^{13} \mathrm{C}\left({ }^{1} \mathrm{H}\right)$ CPMAS NMR spectra were collected using a $90^{\circ}$ pulse length of $6.0 \mu$ s and a ${ }^{1} \mathrm{H}$ spinlocking frequency of $38.5 \mathrm{kHz}$. A contact time of $1 \mathrm{~ms}$ and a recycle delay of $5 \mathrm{~s}$ was used. All spectra were collected under two pulse phase modulated proton decoupling [11,25] with a phase modulation angle of $15^{\circ}$ and a pulse duration of $6.5 \mu \mathrm{s}$ in the ${ }^{1} \mathrm{H}$ channel $\left(90^{\circ}\right.$ pulse length of $3.65 \mu$ s corresponding to an rf field strength of $68.5 \mathrm{kHz}$ ). Approximately 15,000 free induction decays were collected and averaged to obtain each ${ }^{13} \mathrm{C}$ CPMAS NMR spectrum [11].

SiOC ceramic powders were prepared for high-resolution transmission electron microscopy via drop-coating. Thereby PDC powder is mixed with an appropriate solvent, here ethanol was used, and dispersed in an ultrasonic bath. Subsequently, one droplet of the suspension is placed onto a special TEM grid with a carrier carbon film (lacy carbon 
grid). To avoid charging under the incident electron beam, the samples were mildly coated with carbon. TEM/HRTEM investigations were carried out on a JEOL JEM $2100 \mathrm{~F}$ (Jeol, Akishima, Japan) equipped with a Schottky FEG with a nominal acceleration voltage of $200 \mathrm{kV}$. The EDS measurements were recorded with an Oxford XMAX 80 detector (Oxford Instruments plc, Tubney Woods, Abingdon, UK) attached to the microscope. The EELS data were acquired with the spectrometer attached to a JEOL JEM ARM 200F, equipped with a $\mathrm{C}_{\mathrm{s}}$-corrected condenser system, with an acquisition time of $100 \mathrm{~s}$, an energy dispersion of $0.3 \mathrm{eV}$ per channel and an entrance aperture of $5 \mathrm{~mm}$. The energy resolution measured at the zero-loss peak was $0.7-0.8 \mathrm{eV}$.

Calorimetry: The enthalpy of formation from crystalline components of the $800{ }^{\circ} \mathrm{C}$ and $1100{ }^{\circ} \mathrm{C}$ pyrolyzed ceramic samples, HQ0.1_SG, HQ4_SG, HQ8_SG, and $\mathrm{PhSiO}_{1.5}$ SS was measured using high temperature oxide melt solution calorimetry. The sample (1-2 mg) was pressed into a pellet and dropped from room temperature into molten sodium molybdate $\left(3 \mathrm{Na}_{2} \mathrm{O} \bullet \mathrm{MoO}_{3}\right)$ solvent at $800{ }^{\circ} \mathrm{C}$ in a custom-built Tian-Calvet twin microcalorimeter in an oxidizing atmosphere. Oxygen gas was bubbled through the solvent at a rate of $5 \mathrm{~mL} / \mathrm{min}$ to ensure the pellet reacted quickly and that oxidizing conditions were maintained. The gaseous products were flushed out of the system with an oxygen flow of $\sim 90 \mathrm{~mL} / \mathrm{min}$. Eight pellets of each sample were dropped to obtain statistically reliable data. This methodology is well-established $[18,20,26]$ and has been used previously on similar material systems $[15,21,27]$.

\section{Results and Discussion}

\subsection{Synthesis}

The polymers synthesized as described above were pyrolyzed in an argon atmosphere at $800{ }^{\circ} \mathrm{C}$ and $1100{ }^{\circ} \mathrm{C}$, resulting in two types of PDC ceramics, each with its distinct bonding character. While the $\mathrm{PhSiO}_{1.5}$ SG material contained mixed bonding, the HQ4_SG was obtained without mixed bonding, although both polymers contained phenyl as a unique organic group and source of carbon. As shown in Figure 1a, the $\mathrm{PhSiO}_{1.5}$ SG polymer precursor was synthesized to promote direct bonding between the silicon and the carbon of the phenyl group, which is maintained throughout pyrolysis. This polymer obtained is a polyhedral oligomeric silsesquioxane (POSS), as reported in previous studies utilizing a similar synthetic procedure [28]. In Figure 1b, it is illustrated that the silicon bonds to the phenyl through Si-O-C bridges, resulting in a SiOC ceramic without mixed bonding character. Herein, a new polysiloxane was formulated via the reaction of tetramethylorthosilicate with hydroxyquinone (HQ) to form a polysiloxane ceramic without any direct $\mathrm{Si}-\mathrm{C}$ bonds in the structure.

Analysis of the full elemental composition was determined by Mikroanalytisches Labor Pascher in Germany and is tabulated in Table 1, along with the corresponding atomic percentages in parenthesis. The compositional analysis shows that a large amount of carbon was lost during pyrolysis of the HQ4_SG polymer, making impossible the direct comparison of two types of SiOC ceramics with similar compositions. Thus, the focus of this study lies in understanding the relationship between different chemical structures and final nano/micro-structures with or without mixed bonding characteristics. During the HQ4_SG polymer synthesis, it was noted that the color of the sample became brown during the drying process. Polysiloxanes and polysilsesquioxanes are generally white in color as was the case for $\mathrm{PhSiO}_{1.5}$ SG. In air, hydroquinone can partially oxidize to benzoquinone, which actually can be of brown color. Since this synthesis was done under normal atmospheric conditions (air) in water, it is likely that a portion of the hydroquinone oxidized to benzoquinone. Benzoquinone, however, is not able to undergo hydrolysis and condensation reactions and, therefore, the added carbon most likely did not form bonds to the silicon backbone of the polymer, resulting in a significant loss of carbon during pyrolysis. 

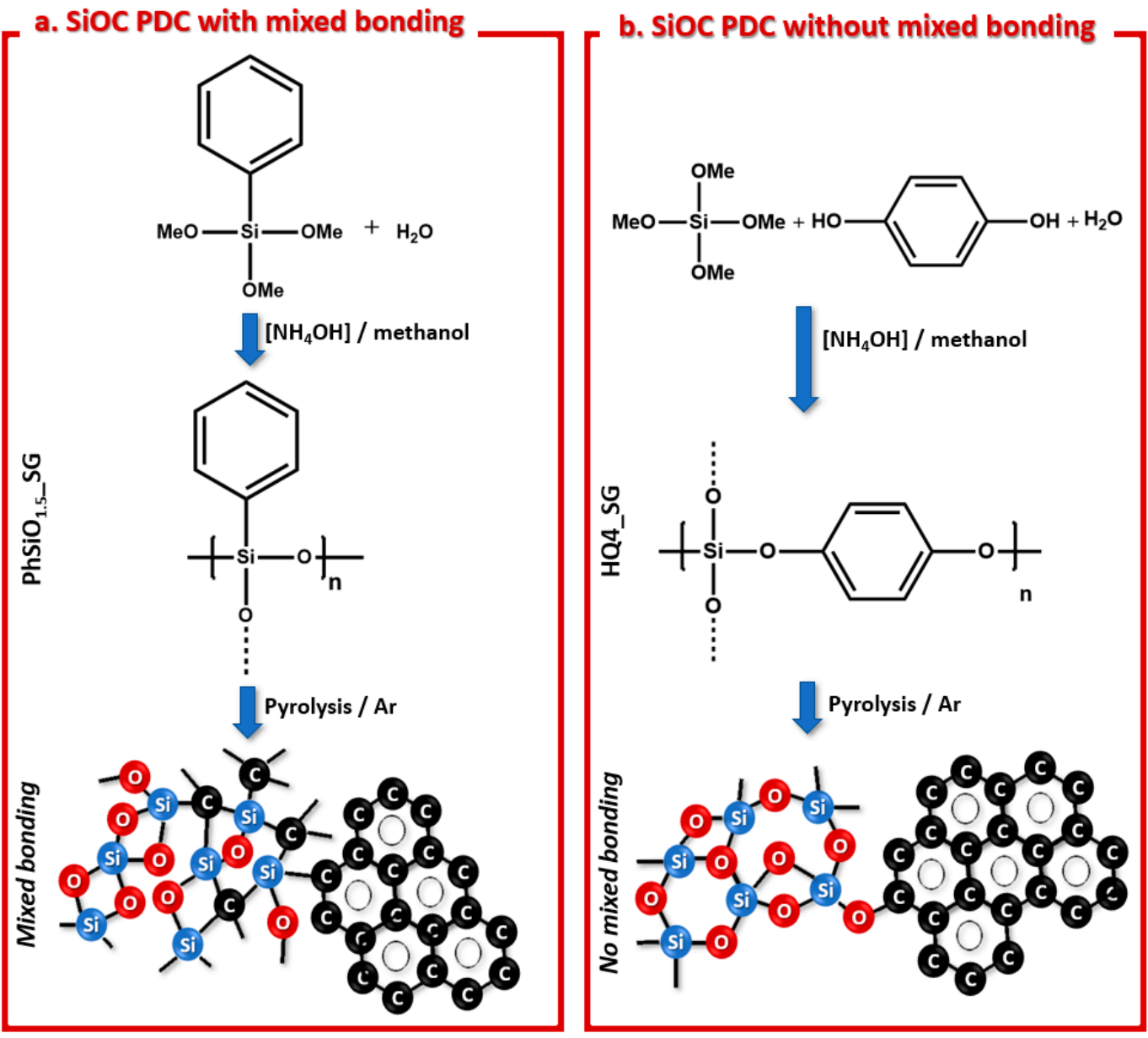

Figure 1. (a) Synthesis of $\mathrm{PhSiO}_{1.5}$ SSG using trimethoxyphenylsilane (TMOPS) precursor to synthesize a polymer with the phenyl group bonding directly to silicon resulting in a SiOC PDC with mixed bonding. (b) Synthesis of HQ4_SG using hydroquinine (HQ) and tetramethylorthosilicate (TMOS) precursors to synthesize a polymer with the phenyl group bonding to the silicon through $\mathrm{Si}-\mathrm{O}-\mathrm{C}$ bridges resulting in a SiOC PDC without mixed bonding.

Table 1. Analyzed composition of $\mathrm{SiOCH}$ ceramic recorded as $\mathrm{wt} \%$ (at.\%).

\begin{tabular}{|c|c|c|c|c|}
\hline Sample & Si (wt.\% (at.\%)) & O (wt.\% (at.\%)) & C (wt.\% (at.\%)) & H (wt.\% (at.\%)) \\
\hline HQ4_SG $800{ }^{\circ} \mathrm{C}$ & $43.3(28.6)$ & $53.4(61.9)$ & $3.05(4.71)$ & $0.26(4.8)$ \\
\hline HQ4_SG $1100{ }^{\circ} \mathrm{C}$ & $42.7(28.3)$ & $50.5(58.8)$ & $5.02(7.78)$ & $0.28(5.2)$ \\
\hline $\mathrm{PhSiO}_{1.5}$ SSG $800^{\circ} \mathrm{C}$ & $24.8(11.2)$ & $28.6(22.7)$ & $44.36(46.98)$ & $1.51(19.1)$ \\
\hline $\mathrm{PhSiO}_{1.5}$ SSG $1100^{\circ} \mathrm{C}$ & $27.2(14.2)$ & $25.1(23.0)$ & $46.51(56.81)$ & $0.41(6.0)$ \\
\hline
\end{tabular}

\subsection{X-ray Powder Diffraction}

The XRD patterns for all PhSiO 1.5 _SG and HQ4_SG pyrolyzed samples are depicted in Figure 2. The amorphous halo found at $2 \theta$ values of $\sim 23^{\circ}$ is caused by overlapping of amorphous silica and the carbon signal. The amorphous halo at $\sim 6^{\circ}$ seen in $\mathrm{PhSiO}_{1.5 \_\mathrm{SG}}$ $800{ }^{\circ} \mathrm{C}$ can be attributed to the cage (cubane) structure formation of polysilsesquioxane [29]. The lack of crystalline $\mathrm{SiC}$ peaks indicates the ceramic remains amorphous at $1100{ }^{\circ} \mathrm{C}$. 


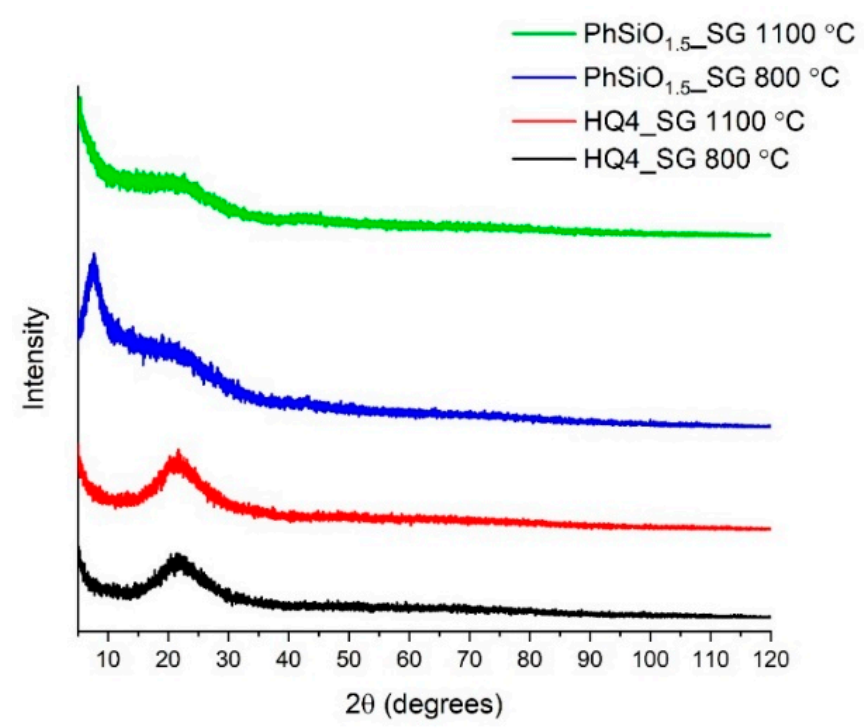

Figure 2. XRD patterns of $\mathrm{PhSiO} 1.5$ SG and HQ4_SG pyrolyzed to $800{ }^{\circ} \mathrm{C}$ and $1100{ }^{\circ} \mathrm{C}$.

\subsection{Fourier Transform Infrared Spectroscopy}

The FTIR results are given in Figures 3 and 4. First, the data of the polymers are presented, followed by the characterization of the pyrolyzed PDCs.

Polymers: The broad bands at $3400 \mathrm{~cm}^{-1}$ assigned to $\mathrm{O}-\mathrm{H}$ stretching [30] are seen in each polymer, most likely caused by $\mathrm{O}-\mathrm{H}$ stretching related to $\mathrm{Si}-\mathrm{OH}$ groups; the result of the hydration of $\mathrm{SiO}_{4}$ tetrahedra. This band is associated with hydrogen-bonded $\mathrm{OH}$ groups on the surface of $\mathrm{SiO}_{2}$ and physisorbed water [31]. Vibration bands between 960 and $990 \mathrm{~cm}^{-1}$ and at $\sim 3650 \mathrm{~cm}^{-1}$ are also indicative of $\mathrm{Si}-\mathrm{OH}$ group bending and asymmetric stretching, respectively [32-35]. The band at $3400 \mathrm{~cm}^{-1}$ is due to nearest neighbor Si-OH groups with strong hydrogen bonding interactions, while the band at $3650 \mathrm{~cm}^{-1}$ can be assigned to $\mathrm{Si}-\mathrm{OH}$ groups that are partially shielded from similar neighboring groups and have weak interactions between the hydrogen of the $\mathrm{Si}-\mathrm{OH}$ group and the oxygen in the $\mathrm{Si}-\mathrm{O}-\mathrm{Si}$ network [22]. The peak at $1027 \mathrm{~cm}^{-1}$ in the $\mathrm{PhSiO}_{1.5}$ SG polymer is assigned to Si-O, a non-bridging oxygen [36], likely present due to incomplete reaction during the condensation process [37]. The bands between 3140 and $2890 \mathrm{~cm}^{-1}$ and the bands at 1594 and $1430 \mathrm{~cm}^{-1}$ in $\mathrm{PhSiO}_{1.5}$ SSG are characteristic of aromatic C-H stretching and phenyl $\mathrm{C}=\mathrm{C}$ bonds $[38,39]$ respectively, confirming that the phenyl R-groups in the polymer are present. Further, the peaks at 738 and $695 \mathrm{~cm}^{-1}$ confirm the presence of monosubstituted benzene [38], again confirming the aromatic substituent is a phenyl R-group. The fact that HQ4_SG polymer does not show any aromatic benzene bands could be due to the aromatic carbon groups starting to roll up into the pores of the polymer, which has been suggested by computations [22]. Bands between 1095 and $1225 \mathrm{~cm}^{-1}$ are assigned to Si-O-Si asymmetric vibrations $[34,40,41]$ for both polymers. The strong band at $1095 \mathrm{~cm}^{-1}$ is also representative of Si-O-C stretching vibration [22]. This band is more pronounced in the HQ4_SG polymer as expected due to $\mathrm{Si}-\mathrm{O}-\mathrm{C}$ bridges used to link the phenyl groups to the polymer backbone.

In $\mathrm{PhSiO}_{1.5}$ SSG, the phenyl R-groups should only be bonded to the silicon in the polymer backbone and a band for $\mathrm{Si}-\mathrm{O}-\mathrm{C}$ stretching mode, if present, would be due to $\mathrm{Si}-\mathrm{O}-\mathrm{CH}_{3}$ end groups of the polymer. Further, HQ4_SG presents a shoulder band at $\sim 1200 \mathrm{~cm}^{-1}$ due to Si-O-Si stretching. The bands between 790 and $795 \mathrm{~cm}^{-1}$, and bands between 460 and $495 \mathrm{~cm}^{-1}$, are assigned to Si-O-Si symmetric bending [22] and O-Si-O bending $[36,41,42]$, respectively. 


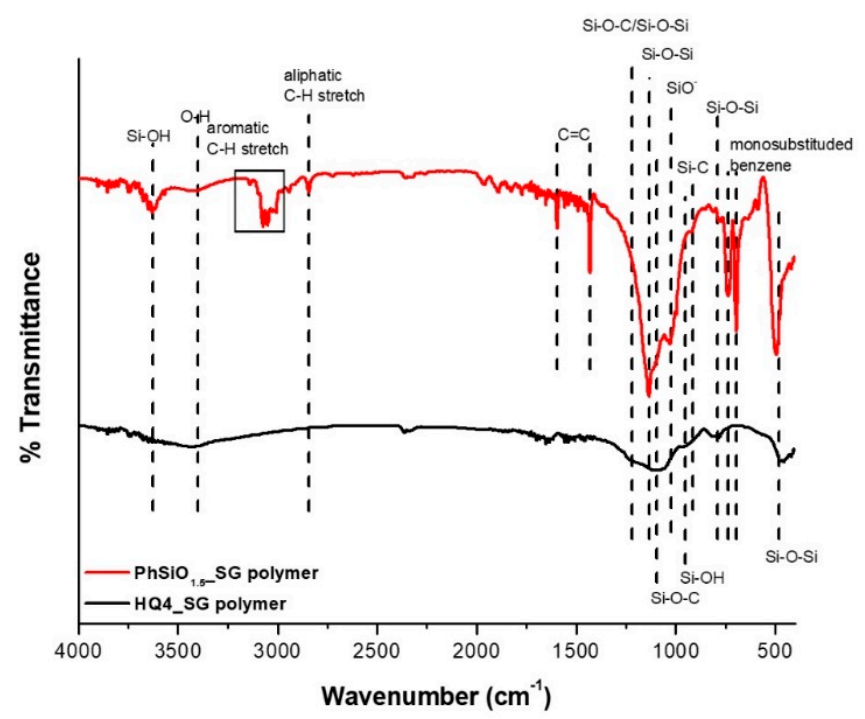

Figure 3. FTIR spectra of $\mathrm{HQ} 4 \_S G$ and $\mathrm{PhSiO}_{1.5}$ SG polymers.
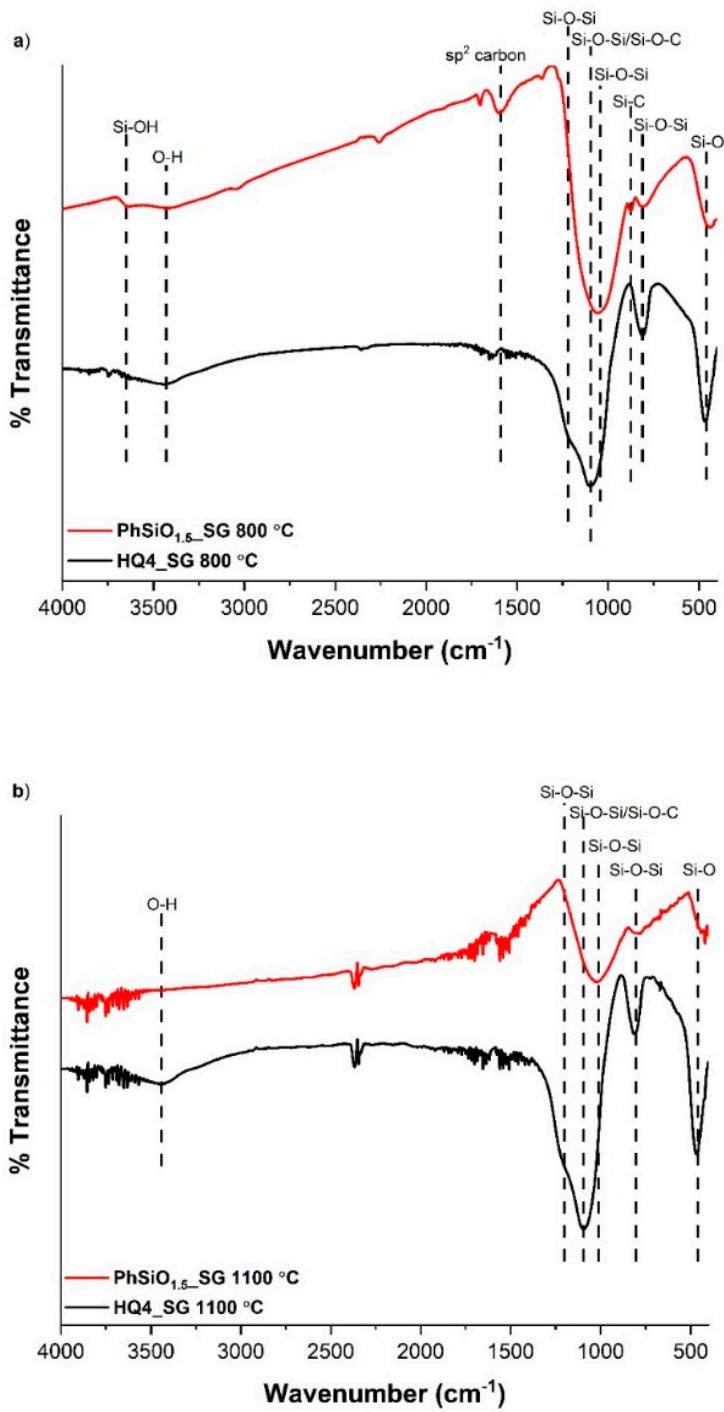

Figure 4. FTIR spectra of HQ4_SG and $\mathrm{PhSiO} 1.5 \mathrm{SG}$ pyrolyzed to (a) $800{ }^{\circ} \mathrm{C}$ and (b) $1100{ }^{\circ} \mathrm{C}$. 
Pyrolyzed PDCs: FTIR revealed key changes that occurred during pyrolysis. In the $\mathrm{PhSiO}_{1.5} \mathrm{SG}$ spectra, the bands for the aromatic $\mathrm{C}-\mathrm{H}$ stretch, phenyl $\mathrm{C}=\mathrm{C}$, and monosubstituted benzene, are no longer present after pyrolysis, indicating that the carbon in the sample transformed from a phenyl group to a $\mathrm{sp}^{2}$ carbon phase. Graphene-like carbons have poor IR transmittance [22] and the lack of bands in the IR spectra, indicating the presence of the "free" carbon phase, is not surprising. The $\mathrm{Si}-\mathrm{C}$ band is still present at $800{ }^{\circ} \mathrm{C}$ at $875 \mathrm{~cm}^{-1}$ but is no longer seen in the FTIR spectra at $1100^{\circ} \mathrm{C}$. A band at $1365 \mathrm{~cm}^{-1}$ has been assigned to $\mathrm{Si}-\mathrm{CH}_{2}-\mathrm{Si}$ bending $[37,41,43]$. This $\mathrm{Si}-\mathrm{C}-\mathrm{Si}$ linkage is evidence of the direct $\mathrm{Si}-\mathrm{C}$ bonds that could indicate the presence of $\mathrm{Si}-\mathrm{C}$ bonding at the interface between the silica and "free" carbon in a SiOC PDC with mixed bonding. The fact that this band is not observed after pyrolysis at $1100{ }^{\circ} \mathrm{C}$ is likely due to the loss of hydrogen at higher temperatures Bands between 1000-1225 $\mathrm{cm}^{-1}$ result from Si-O-Si asymmetric stretching vibrations and are seen in all pyrolyzed samples. This asymmetric stretching vibration band in $\mathrm{PhSiO}_{1.5}$ SG occurs at $\sim 1040 \mathrm{~cm}^{-1}$ for the sample pyrolyzed at $800{ }^{\circ} \mathrm{C}$, and at $\sim 1010 \mathrm{~cm}^{-1}$ for the sample pyrolyzed at $1100{ }^{\circ} \mathrm{C}$, while in the HQ4_SG samples it occurs at $\sim 1100 \mathrm{~cm}^{-1}$. The presence of framework defects results in shifts to lower values in FTIR spectra [22], which is directly related to the $\mathrm{Si}-\mathrm{O}-\mathrm{Si}$ bond angles. A comparison of the asymmetric stretching $\mathrm{Si}-\mathrm{O}-\mathrm{Si}$ mode for $\mathrm{PhSiO}_{1.5}$ SG and HQ4_SG samples indicates that inserting carbon into the silica framework when mixed bonding is present, has the most impact on the band shift, as noted by the $\mathrm{Si}-\mathrm{O}-\mathrm{Si}$ asymmetric band in $\mathrm{PhSiO}_{1.5} \mathrm{SG}_{\mathrm{S}}$ shifting to lower wavenumbers. When carbon is substituted into the silica framework, as in SiOCs with mixed bonding, the wavenumber of the associated $\mathrm{Si}-\mathrm{O}-\mathrm{Si}$ asymmetric stretching band is lowered as a result of the bond angle decrease [44].

The O-H stretching band present in both HQ4_SG samples, as well as the high hydrogen content seen in the compositional analysis, indicates that the structure is a composite of amorphous silica and $\mathrm{sp}^{2}$ carbon with terminal $-\mathrm{OH}$ groups on the silicon tetrahedra [45-47]. An intense band at $1095 \mathrm{~cm}^{-1}$ could also be caused by overlapping $\mathrm{Si}-$ $\mathrm{O}-\mathrm{Si} / \mathrm{Si}-\mathrm{O}-\mathrm{C}$ stretching modes and is present as the most intense band in both pyrolyzed HQ4_SG samples. This band could be indicative of covalent bonding at the interface between the silica and "free" carbon nanodomains or it could just be due to the $\mathrm{Si}-\mathrm{O}-\mathrm{Si}$ of the silica network.

\subsection{Magic Angle Spinning Nuclear Magnetic Resonance}

The ${ }^{29} \mathrm{Si}$ MAS NMR of both $\mathrm{PhSiO}_{1.5}$ SSG samples, shown in Figure $5 \mathrm{a}, \mathrm{b}$, have peaks at $\sim-04,-72,-38,-11$ and $7 \mathrm{ppm}$, which are characteristic peaks for $\mathrm{SiO}_{4}, \mathrm{SiO}_{3} \mathrm{C}, \mathrm{SiO}_{2} \mathrm{C}_{2}$, $\mathrm{SiC}_{4}$ and $\mathrm{SiOC}_{3}$ respectively [11,48]. For the sample pyrolyzed at $800{ }^{\circ} \mathrm{C}$, the $\mathrm{SiO}_{4}$ peak is at $\sim-102 \mathrm{ppm}$ and at $1100^{\circ} \mathrm{C}$ the peak is shifted to $\sim-107 \mathrm{ppm}$. One explanation for the downfield shift in the $800^{\circ} \mathrm{C}$ sample is the presence of terminal hydroxyl groups on the silica. The ${ }^{29} \mathrm{Si}$ chemical shift is very sensitive to the chemical environment of $\mathrm{Si}$ atoms in silicates and just one terminal -OH group on a silica tetrahedron will cause a chemical shift downfield. As seen in the FTIR for the $\mathrm{PhSiO}_{1.5}$ SG samples, there is $\mathrm{OH}$ present in the $800{ }^{\circ} \mathrm{C}$ sample, but not in the $1100{ }^{\circ} \mathrm{C}$ sample. The compositional analysis also shows a decrease in the hydrogen content for the $1100^{\circ} \mathrm{C}$ sample which is likely due to the loss of water during pyrolysis to the higher temperature. These results both support the conclusion that the downfield shift seen in the ${ }^{29}$ Si MAS NMR data is caused by terminal hydroxyl groups on the silica tetrahedra. 
a)

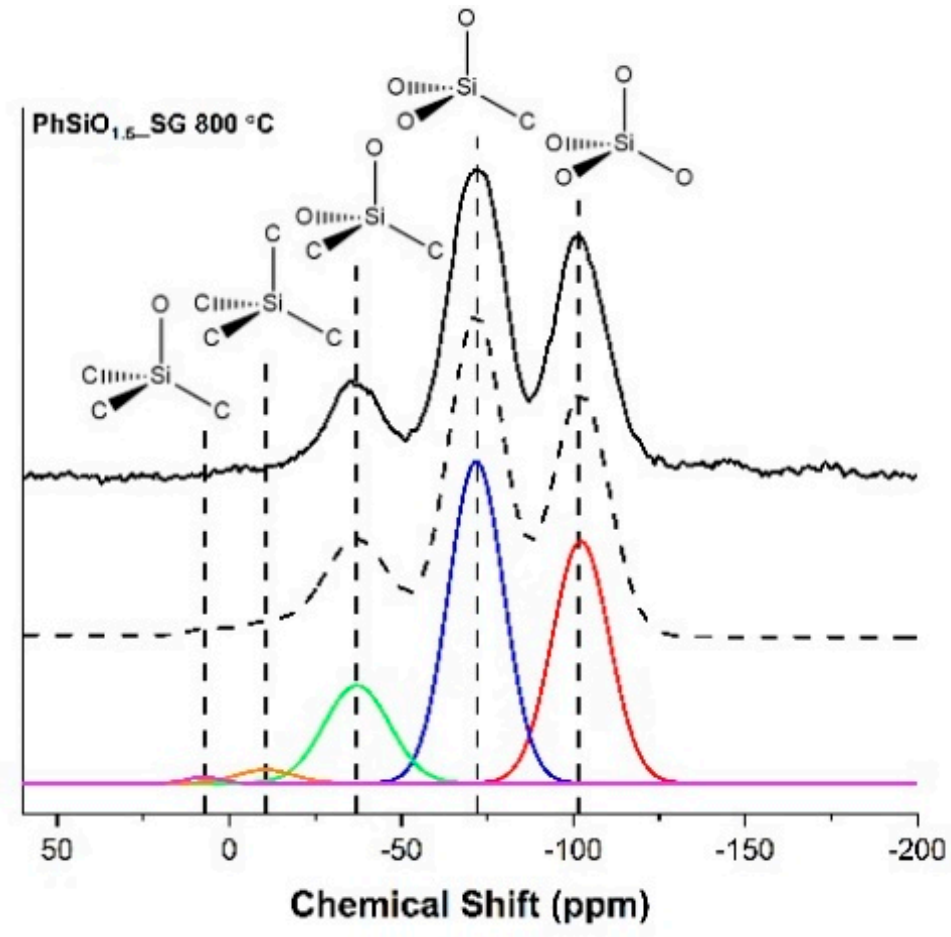

b)

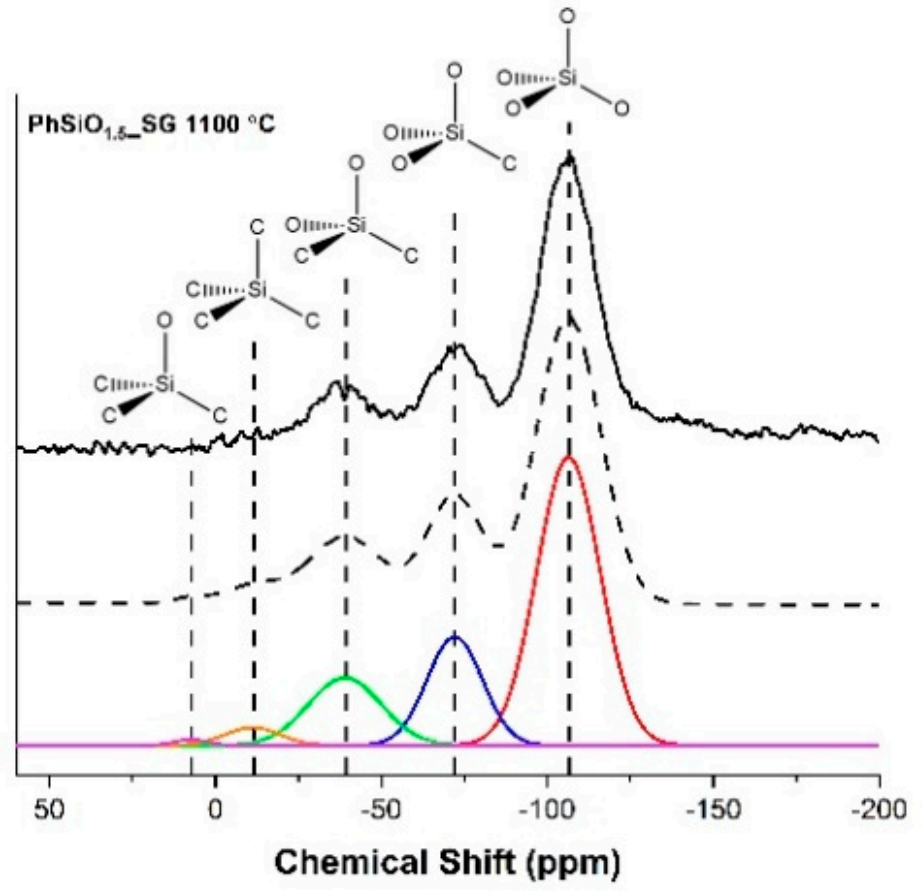

Figure 5. ${ }^{29} \mathrm{Si}$ MAS NMR for $\mathrm{PhSiO}_{1.5}$ SG samples. (a) Sample pyrolyzed to $800{ }^{\circ} \mathrm{C}$ with peaks at -102 ppm, $-72 \mathrm{ppm},-38 \mathrm{ppm},-11 \mathrm{ppm}$ and $7 \mathrm{ppm}$, corresponding to $\mathrm{SiO}_{4}, \mathrm{SiO}_{3} \mathrm{C}$, and $\mathrm{SiO}_{2} \mathrm{C}_{2}$, $\mathrm{SiC}_{4}$ and $\mathrm{SiOC}_{3}$ tetrahedra, respectively. (b) Sample pyrolyzed to $1100{ }^{\circ} \mathrm{C}$ with peaks at $-107 \mathrm{ppm}$, $-72 \mathrm{ppm},-38 \mathrm{ppm},-11 \mathrm{ppm}$ and $7 \mathrm{ppm}$ corresponding to the same structural units given in (a). 
The percentage of each $\mathrm{SiO}_{\mathbf{x}} \mathrm{C}_{4-\mathrm{x}}$ mixed bond species, shown in Table 2, was calculated using the deconvoluted peaks from each ${ }^{29}$ Si MAS NMR spectrum. The $\mathrm{PhSiO}_{1.5 \_S G}$ sample pyrolyzed to $800{ }^{\circ} \mathrm{C}$ has a larger percentage of mixed bonding overall. A study by T. Liang et. al. [49] determined the effect of water in the pyrolysis environment. The pyrolysis of a polysiloxane in a mixture of argon and water vapor resulted in a SiOC with less mixed bonding than the same polysiloxane pyrolyzed in dry argon. $\mathrm{PhSiO}_{1.5} \mathrm{SG}_{\mathrm{S}}$ has a relatively high hydrogen content, being higher at the lower pyrolysis temperature, which indicates that less water has been released. It is therefore likely that the water content evolved during pyrolysis at higher temperatures results in a lower percentage of mixed bonding in this sample.

Table 2. Percentage of each $\mathrm{SiO}_{x} \mathrm{C}_{4-x}$ Si species calculated from ${ }^{29} \mathrm{Si}$ MAS NMR.

\begin{tabular}{|c|c|c|c|c|c|}
\hline \multirow{2}{*}{ Sample } & \multicolumn{5}{|c|}{ Si Species (\%) } \\
\hline & $\mathrm{SiO}_{4}$ & $\mathrm{SiO}_{3} \mathrm{C}$ & $\mathrm{SiO}_{2} \mathrm{C}_{2}$ & $\mathrm{SiOC}_{4}$ & $\mathrm{SiC}_{4}$ \\
\hline $\mathrm{PhSiO}_{1.5} \_\mathrm{SG} 800^{\circ} \mathrm{C}$ & 35.55 & 45.57 & 16.44 & 0.51 & 1.93 \\
\hline $\mathrm{PhSiO}_{1.5}$ SSG $1100{ }^{\circ} \mathrm{C}$ & 60.20 & 19.77 & 16.23 & 0.61 & 3.19 \\
\hline
\end{tabular}

The ${ }^{29}$ Si MAS NMR of HQ4_SG, shown in Figure 6a,b, indicates that the silicon bonding environment is different compared to the $\mathrm{PhSiO}_{1.5}$ SG sample. The biggest difference is the absence of peaks that correspond to carbon substitution in the $\mathrm{SiO}_{4}$ tetrahedra in HQ4_SG. This confirms that there is very little or no mixed bonding in the HQ4_SG samples, but rather that this material is similar to a composite of silica with a minor fraction of $\mathrm{sp}^{2}$ "free" carbon. Consequently, the ${ }^{29}$ Si MAS NMR spectra for both HQ4_SG samples are composed of pure amorphous silica units with three isotropic peaks at -110, -99 and -91 ppm, corresponding to $\mathrm{SiO}_{4}\left(\mathrm{Q}^{4}\right), \mathrm{SiO}_{3}(\mathrm{OH})\left(\mathrm{Q}^{3}\right)$ and $\mathrm{SiO}_{2}(\mathrm{OH})_{2}\left(\mathrm{Q}^{2}\right)$ [50-52], respectively.

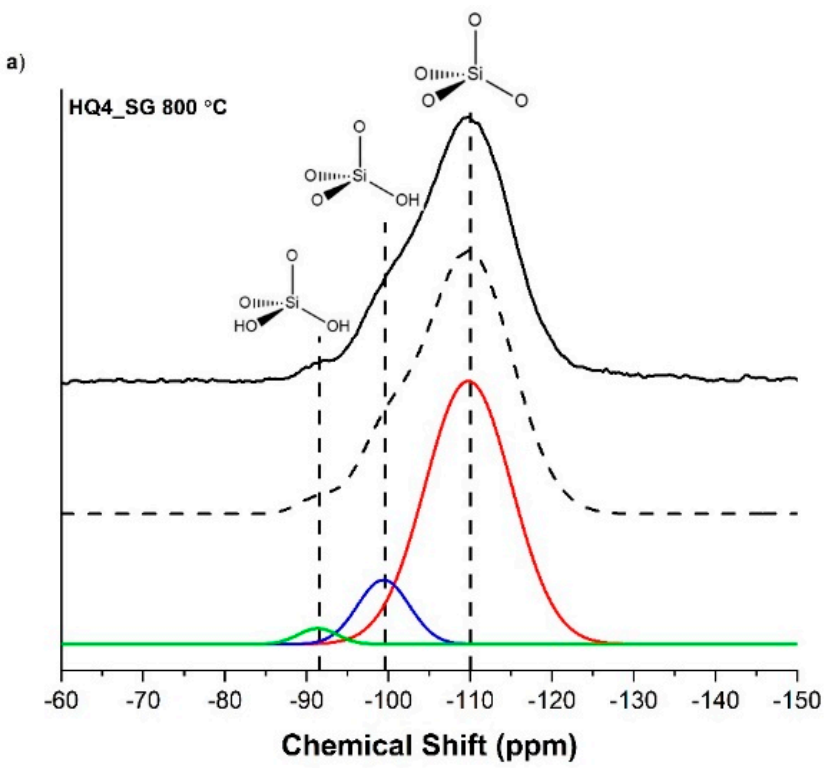

Figure 6. Cont. 


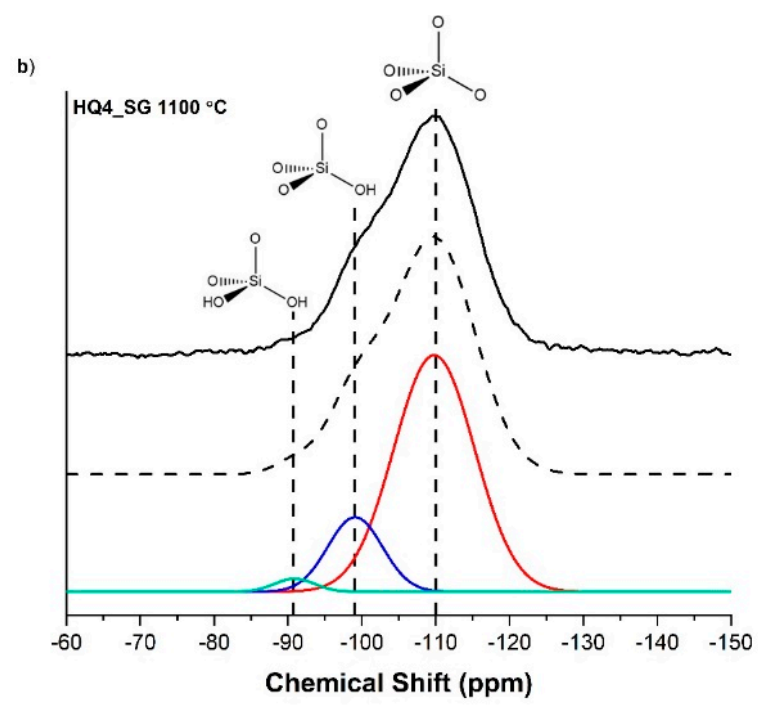

Figure 6. ${ }^{29}$ Si MAS NMR for HQ4_SG samples with peaks at -110 ppm, $-100 \mathrm{ppm}$ and $-92 \mathrm{ppm}$, corresponding to $\mathrm{SiO}_{4}, \mathrm{SiO}_{3}(\mathrm{OH})$ and $\mathrm{SiO}_{2}(\mathrm{OH})_{2}$ tetrahedra, respectively; for (a) the sample pyrolyzed to $800{ }^{\circ} \mathrm{C}$ and (b) the sample pyrolyzed to $1100{ }^{\circ} \mathrm{C}$.

The percentage of each $\mathrm{Q}^{\mathrm{n}}$ species, shown in Table 3, was calculated using the area under the curve of the deconvoluted peaks for each $\mathrm{Si}$ tetrahedron. The percentages of each $\mathrm{Q}^{\mathrm{n}}$ species are consistent with sol-gel synthesis in basic conditions of silica, which tends to have a higher percentage of $\mathrm{Q}^{4}$ silica tetrahedra than materials synthesized in acidic conditions [53].

Table 3. Percentage of each $\mathrm{Q}^{\mathrm{n}} \mathrm{Si}$ species calculated from ${ }^{29} \mathrm{Si}$ MAS NMR.

\begin{tabular}{cccc}
\hline Sample & \multicolumn{3}{c}{$\mathbf{Q}^{\text {n Si Species }(\%)}$} \\
$\mathbf{S i O}_{\mathbf{3}}(\mathbf{O H})\left(\mathbf{Q}^{\mathbf{3}}\right)$ & $\mathbf{S i O}_{\mathbf{2}}(\mathbf{O H})_{\mathbf{2}}\left(\mathbf{Q}^{\mathbf{4}}\right)$ \\
\hline HQ4_SG 800 & 85.2 & 12.5 & 2.3 \\
HQ4_SG 1100 & 80.6 & 17.2 & 2.2 \\
\hline
\end{tabular}

\section{5. ${ }^{13} \mathrm{C}\left({ }^{1} \mathrm{H}\right)$ Cross Polarization Magic Angle Spinning Nuclear Magnetic Resonance}

The ${ }^{13} \mathrm{C}$ CPMAS NMR spectra for the $\mathrm{PhSiO}_{1.5}$ SG samples, given in Figure 7, have the characteristic isotropic chemical shift for $\mathrm{sp}^{2}$ carbon at $\sim 127 \mathrm{ppm}$, with spinning side bands at $242,186,74,17$ and $-36 \mathrm{ppm}$, caused by the chemical shift anisotropy (CSA) [11]. ${ }^{13} \mathrm{C}$ solid state MAS NMR peaks of aromatic carbons in various carbon materials ranges from 110 to $160 \mathrm{ppm}$, while peaks of aliphatic carbons range from 0 to $90 \mathrm{ppm}[54,55]$. In contrast, graphite and turbostratic carbon ${ }^{13} \mathrm{C}$ NMR peaks range between $\sim 120$ and $130 \mathrm{ppm}[56,57]$. The isotropic peak in $\mathrm{PhSiO}_{1.5}{ }_{-} \mathrm{SG}$ is therefore assigned to $\mathrm{sp}^{2}$ hybridized carbon in the form of graphite or turbostratic carbon. This carbon represents the "free" carbon phase of the SiOCH. Given the mixed bonding peaks seen in the ${ }^{29} \mathrm{Si}$ MAS NMR spectra, it would be expected to see a peak from $\mathrm{sp}^{3}$ hybridized carbon in the range typical for silicon carbide of 10-25 ppm [58]. Although it is not obvious for either $\mathrm{PhSiO}_{1.5}$ SSG sample in the ${ }^{13} \mathrm{C}$ NMR spectra that $\mathrm{sp}^{3}$ carbon is present, it is possible there is a small peak at $\sim 18 \mathrm{ppm}$ that overlaps with a spinning side band. The spectra of $\mathrm{PhSiO}_{1.5}$ SG pyrolyzed at $800{ }^{\circ} \mathrm{C}$ were fitted with an $\mathrm{sp}^{3}$ peak at $18 \mathrm{ppm}$ to demonstrate this aspect. In the simulated spectrum, adding the $\mathrm{sp}^{3}$ carbon peak results in a peak at $18 \mathrm{ppm}$ that fits more closely to the observed intensity, indicating that it is quite possible that this peak is present. Due to the background noise of the spectrum of the $1100{ }^{\circ} \mathrm{C}$ sample, it is more difficult to determine whether an overlapping peak is present and therefore a simulation with an additional $\mathrm{sp}^{3}$ peak was omitted. 

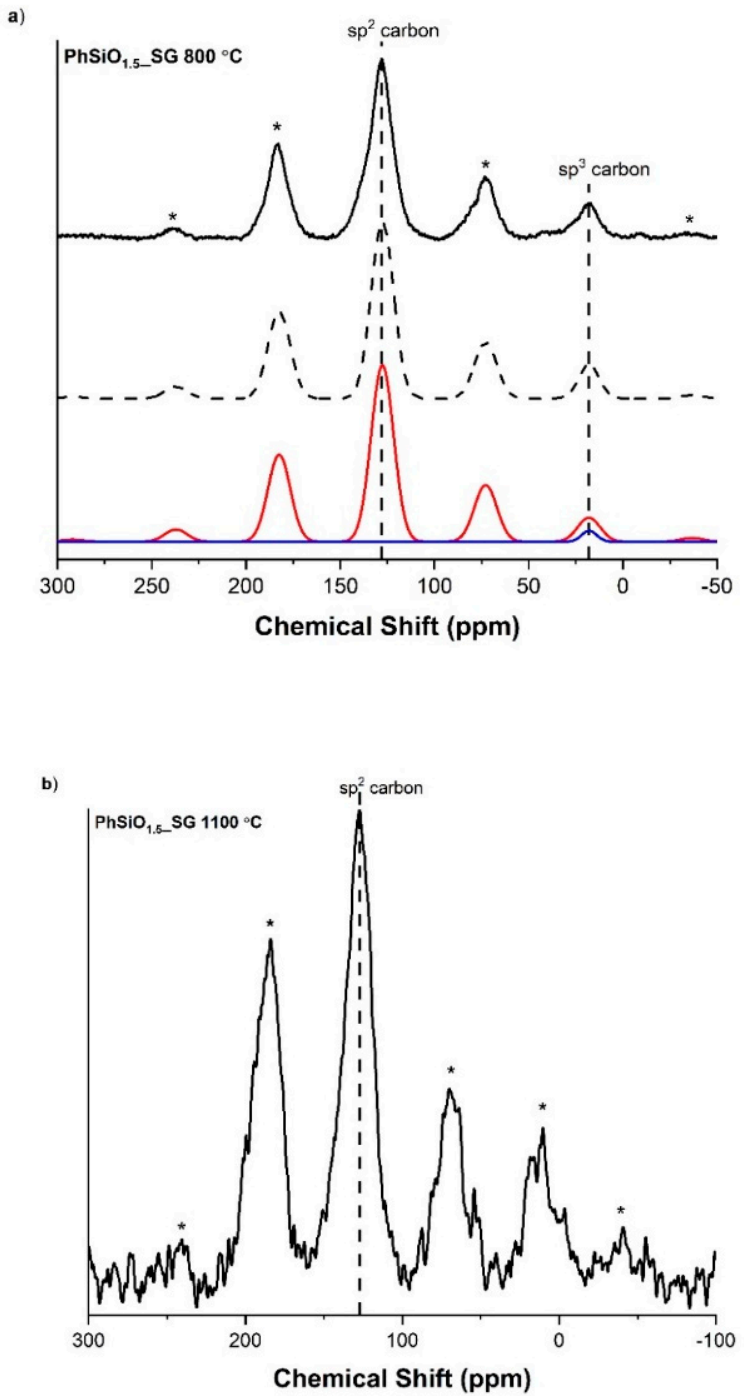

Figure 7. ${ }^{13} \mathrm{C}\left({ }^{1} \mathrm{H}\right)$ CPMAS NMR for $\mathrm{PhSiO}_{1.5}$ SG samples. (a) Sample pyrolyzed to $800{ }^{\circ} \mathrm{C}$ with peaks at $\sim 127 \mathrm{ppm}$ and $18 \mathrm{ppm}$, corresponding to $\mathrm{sp}^{2}$ hybridized carbon and $\mathrm{sp}^{3}$ hybridized carbon, respectively. (b) Sample pyrolyzed to $1100{ }^{\circ} \mathrm{C}$ with an isotropic peak at $\sim 127 \mathrm{ppm}$, corresponding to $\mathrm{sp}^{2}$ hybridized carbon. The stars * denote spinning side bands.

The spectra for HQ4_SG samples are shown in Figure 8. These spectra are not very well resolved due to possible overlapping carbon signals. Each of the spectra were fitted with three isotropic peaks at 125,104 and 26 ppm, assigned to sp ${ }^{2}$ graphitic carbon, carbon nanotubes (CNTs)/carbon nanoscrolls (CNSs) and $\mathrm{sp}^{3}$ carbon, respectively. The graphitic carbon peak in each spectrum was also assigned here, similar to the $\mathrm{PhSiO}_{1.5}$ SG sample. The CNT/CNS peak can explain the overall broadening of the spectra. In general, peaks in ${ }^{13} \mathrm{C}$ MAS NMR spectra of single walled CNTs are broad due to the inhomogeneous dispersion of chemical shifts caused by differing nanotube chiralities, lengths and adjacent defects [59-62]. Multi walled CNTs on the other hand show broadening in the isotropic peak mainly due to diamagnetic shielding $[63,64]$ caused by CNTs enclosed by other CNTs [65] The graphitic $\mathrm{sp}^{2}$ carbon peak is thought to simply originate from an aromatic carbon network that has not fully reacted to form rolled-up structures. The third possible peak seen in the ${ }^{13} \mathrm{C}\left({ }^{1} \mathrm{H}\right)$ MAS NMR spectra of HQ4_SG is at 26 ppm. This peak is in the range of aliphatic carbon [54] underlining the presence of carbon nanoscrolls with saturated edges instead of CNTs. Note that no evidence of Si-C bonding in these samples was found in the corresponding ${ }^{29} \mathrm{Si}$ MAS NMR spectra. 

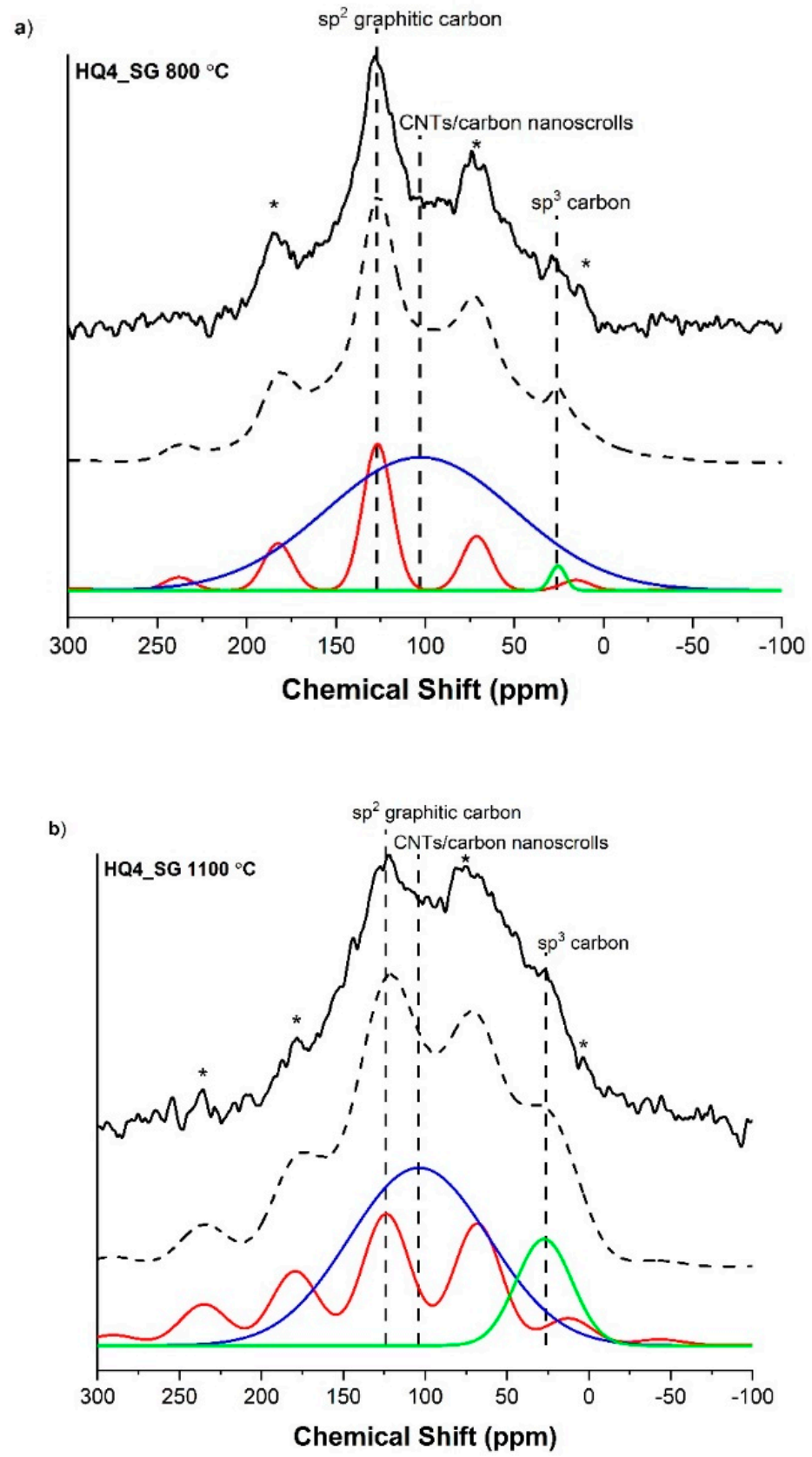

Figure 8. ${ }^{13} \mathrm{C}\left({ }^{1} \mathrm{H}\right)$ CPMAS NMR of the HQ4_SG samples with isotropic peaks at $127 \mathrm{ppm}, 103 \mathrm{ppm}$ and $26 \mathrm{ppm}$, corresponding to $\mathrm{sp}^{2}$ hybridized graphitic carbon, CNT/carbon nanoscrolls and $\mathrm{sp}^{3}$ hybridized carbon, respectively; for (a) the sample pyrolyzed to $800{ }^{\circ} \mathrm{C}$ and (b) the sample pyrolyzed at $1100{ }^{\circ} \mathrm{C}$. The stars * denote spinning side bands.

\subsection{Micro-Raman Spectroscopy}

The Raman spectra of all $\mathrm{PhSiO}_{1.5}$ _SG and HQ4_SG samples, depicted in Figure 9, have extensive noise introduced due to fluorescence in the samples when using a $514.5 \mathrm{~nm}$ laser source. Despite this, clear D and G bands are seen at $1330 \mathrm{~cm}^{-1}$ and $1600 \mathrm{~cm}^{-1}$, which is consistent with $\mathrm{sp}^{2}$ carbon, where the characteristic Raman bands are the disordered carbon $\mathrm{D}$ band at $\sim 1350 \mathrm{~cm}^{-1}$ and the in-plane bond stretching $\mathrm{G}$ band at $\sim 1590 \mathrm{~cm}^{-1}$, as also seen in the fitted Raman spectra in Figure 9. Additional bands at $\sim 105 \mathrm{~cm}^{-1}$ and $150 \mathrm{~cm}^{-1}$ are assigned to radial like breathing modes (RBLMs). These bands are similar to those reported for CNTs as low energy active Raman modes that result in bands due to the radial breathing modes. These radial breathing modes are a result of the synchronous expanding and contracting of the nanotube in the radial direction $[66,67]$. Thus, the 
RBM position is related to the diameter of the CNT and is not seen in other types of $\mathrm{sp}^{2}$ carbon [68]. When the carbon phase is rolled up in the pores of silica, it can form carbon nanoscrolls that have more than one RLBM band, as opposed to SWCNTs, which are expected to have only one RBM [22]. The RLBM bands of HQ4_SG samples are shifted slightly to lower wavenumber, which indicates different diameters of the nanoscrolls [69]. After $200 \mathrm{~cm}^{-1}$, the overtone of the fluorescence is too strong, and no other bands are seen. From the Raman data, it is concluded that spiral-like structures with rolled-up geometry and open edges are present in these samples, in particular in the HQ4_SG $800{ }^{\circ} \mathrm{C}$ sample, however, further analysis is necessary to determine their specific nature.
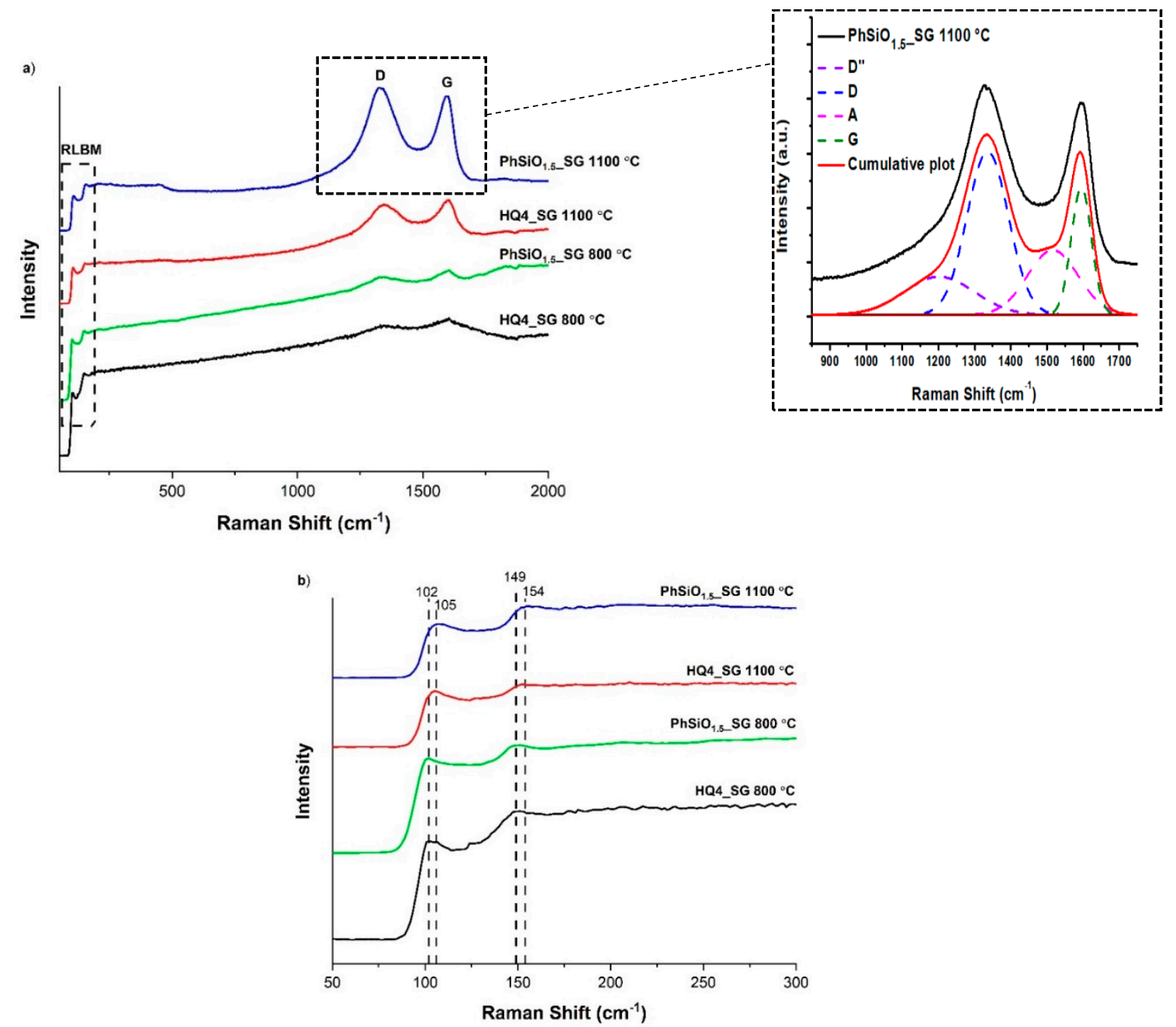

Figure 9. Raman spectra of $\mathrm{PhSiO}_{1.5}$ _SG and HQ4_SG samples. (a) The entire spectra from 50 to $2000 \mathrm{~cm}^{-1}$ with inset showing the Raman fitting of $\mathrm{PhSiO}_{1.5}$ SG $1100{ }^{\circ} \mathrm{C}$ and (b) the spectra from 50 to $300 \mathrm{~cm}^{-1}$ to show details of the RLBM bands.

The fitting of $\mathrm{D}$ and $\mathrm{G}$ bands offers the possibility to evaluate the carbon-cluster size $\mathrm{L}_{\mathrm{a}}$ by using the formula reported by Cançado (Equation (1)) [70].

$$
L_{a}(\mathrm{~nm})=\frac{560}{E_{l}^{4}}\left[\frac{A_{D}}{A_{G}}\right]^{-1}
$$

with $L_{a}$ being the size of the carbon domains along the six-fold ring plane (lateral size between line defects), $E_{l}$ the energy of the laser used in the study ( $2.41 \mathrm{eV}$ corresponding to the laser wavelength of $514.5 \mathrm{~nm}$ ) and $A_{D} / A_{G}$ the intensity ratio of the $D$ and $G$ modes. 
Lorentzian and Gaussian curve fitting of the Raman bands was performed in order to extract the $A_{D} / A_{G}$ intensity ratios and to determine the size of the free carbon clusters formed in the PDC ceramics. The peak fitting was done including the minor $D^{\prime \prime}$ and $A$ bands (see inset in Figure 9a). There is a strong dependency of the $A_{D} / A_{G}$ ratio on the degree of disorder in graphene-like materials [71]. The disorder is quantified as a function of point-like defects, precisely on the inter-defect distance, $L_{D}$, as calculated with Equation (2). As reference, for pristine graphene $L_{D} \rightarrow \infty$ and for fully disordered graphene $L_{D} \rightarrow 0$.

$$
L_{D}(\mathrm{~nm})=\sqrt{\frac{4300}{E_{L}^{4}\left(e V^{4}\right)}\left[\frac{A_{D}}{A_{G}}\right]^{-1}}
$$

The inter-defect distances $L_{D}$, the lateral cluster sizes $L_{a}$ and the ratio of $D$ and $G$ are summarized in Table 4.

Table 4. Raman graphitization parameters for all samples reported in this study.

\begin{tabular}{|c|c|c|c|c|c|c|}
\hline Sample & $\begin{array}{c}\omega_{\mathrm{D}} \\
\left(\mathrm{cm}^{-1}\right)\end{array}$ & $\begin{array}{c}\omega_{\mathrm{G}} \\
\left(\mathrm{cm}^{-1}\right)\end{array}$ & $A_{D} / A_{G}$ & $\begin{array}{c}L_{a} \\
(\mathrm{~nm})\end{array}$ & $\begin{array}{c}L_{D} \\
(\mathrm{~nm})\end{array}$ & $\begin{array}{c}o \\
\left(1 / \mathrm{nm}^{2}\right)\end{array}$ \\
\hline HQ4_SG $800^{\circ} \mathrm{C}$ & 1345 & 1599 & 0.9 & 44.2 & 18.4 & 0.0029 \\
\hline HQ4_SG $1100^{\circ} \mathrm{C}$ & 1350 & 1601 & 2.9 & 13.1 & 10.0 & 0.0099 \\
\hline $\mathrm{PhSiO}_{1.5}$ SSG $800^{\circ} \mathrm{C}$ & 1335 & 1595 & 2.3 & 16.2 & 11.1 & 0.0080 \\
\hline $\mathrm{PhSiO}_{1.5}$ SGG $1100{ }^{\circ} \mathrm{C}$ & 1333 & 1597 & 5.5 & 6.8 & 7.2 & 0.0190 \\
\hline
\end{tabular}

$\omega$ represents the exact wavenumber position of the respective Raman band.

As observed in Table 4, there is a blue shift of the D bands of HQ4_SG samples at both 800 and $1100{ }^{\circ} \mathrm{C}$ as compared with the $\mathrm{PhSiO}_{1.5}$ SG ceramics. The blue shift originates from compression and a quantum effect of the carbon lattice into the silica porous matrix. This observation underlines the fundamental structural difference in-between the carbon phase of the SiOC ceramic samples with and without mixed bonds in their structure. The large compressive stress affecting the $\mathrm{C}=\mathrm{C}$ bonds in a highly defective carbon phase can be observed also by the blue shift of the $G$ band at $\sim 1600 \mathrm{~cm}^{-1}$, as compared to other carbonaceous materials.

A relatively high $A_{D} / A_{G}$ ratio (2.3 to 5.5 as a sign of disorder) was registered for all samples, except for HQ4_SG 800. The slight disorder of the samples is also underlined by the presence of the $\mathrm{D}^{\prime \prime}$ band (shoulder at $\sim 1150-1200 \mathrm{~cm}^{-1}$ being attributed to the presence of $\mathrm{sp}^{2}-\mathrm{sp}^{3} \mathrm{C}-\mathrm{C}$ and $\mathrm{C}=\mathrm{C}$ bonds) and of the $\mathrm{A}$ band (at $\sim 1500 \mathrm{~cm}^{-1}$, corresponding to the fraction of amorphous carbon contained in the samples). The disorder originates from the presence of $\mathrm{sp}^{3}$ hybridized $C$ edges of the graphene scrolled layers and of the pores, as shown also by the MAS NMR study. The lateral size $L_{a}$ (between line defects) follows the same trend as the $A_{D} / A_{G}$ ratio with the lowest value (highest disorder) for the sample $\mathrm{PhSiO}_{1.5}$ SSG_1100 ${ }^{\circ} \mathrm{C}(6.8 \mathrm{~nm})$ and the highest value (highest order) for the HQ4_SG $800{ }^{\circ} \mathrm{C}$ sample $(44.2 \mathrm{~nm})$. For both types of $\mathrm{SiOC}$ ceramics, with and without mixed bonds, the structural rearrangements seem to increase disorder at $1100^{\circ} \mathrm{C}$ as compared to $800^{\circ} \mathrm{C}$. For the $\mathrm{PhSiO}_{1.5}$ SG samples, the release of hydrogen from 800 to $1100{ }^{\circ} \mathrm{C}$ is probably a key factor for the increase in the disorder with increasing temperature. The observed trend for the lateral carbon size $L_{a}$ was followed by the inter-defect distance $L_{D}$ (point-like defects), providing the lowest defect density for the sample HQ4_SG $800{ }^{\circ} \mathrm{C}$ and the highest defect density for $\mathrm{PhSiO}_{1.5} \_\mathrm{SG} 1100{ }^{\circ} \mathrm{C}$.

\subsection{High-Resolution Transmission Electron Microscopy}

To investigate the local microstructural evolution of the SiOC ceramics with or without mixed bonding structure and, in addition, to gain information on the nature and organization of possible nanocarbon phases present in both materials, transmission electron microscopy (TEM) in conjunction with energy-dispersive X-ray spectroscopy (EDS) and electron energy loss spectroscopy (EELS) were performed. Here, both samples synthesized at the lower pyrolysis temperature of $800{ }^{\circ} \mathrm{C}$ were compared, in order to analyze the early 
stage of polymer-to-ceramic transition. As shown in Figure 10, both samples are completely amorphous, as can be seen from the diffuse halos in the FFT/SAED images (see insets in (a) and (c)), being consistent with the XRD-data presented in Figure 2. In addition, the inverse Fast-Fourier-Transform (Inv-FFT) images given in the insets of Figure 10b,d, also reveal no indication of local ordering or the initiation of local nucleation. This finding is in general, not unexpected, considering the relatively low pyrolysis temperature of $800^{\circ} \mathrm{C}$. However, a rather unexpected result of the HRTEM imaging is that no indication of the presence of any carbon phase, even not for the PhSiO1.5_SG $800{ }^{\circ} \mathrm{C}$ sample, could be observed. As shown in Table 1, the chemical analysis of PhSiO1.5_SG $800{ }^{\circ} \mathrm{C}$ gave a carbon content of ca. 44 wt.\%, which was expected to be "seen". On the other hand, considering a high volume fraction of highly disordered or even amorphous carbon being present in this sample, a distinction from the at such pyrolysis temperature typically amorphous SiOC matrix phase will not be possible by HRTEM, in particular, since basically only light elements, with the exception of Si compose both materials.
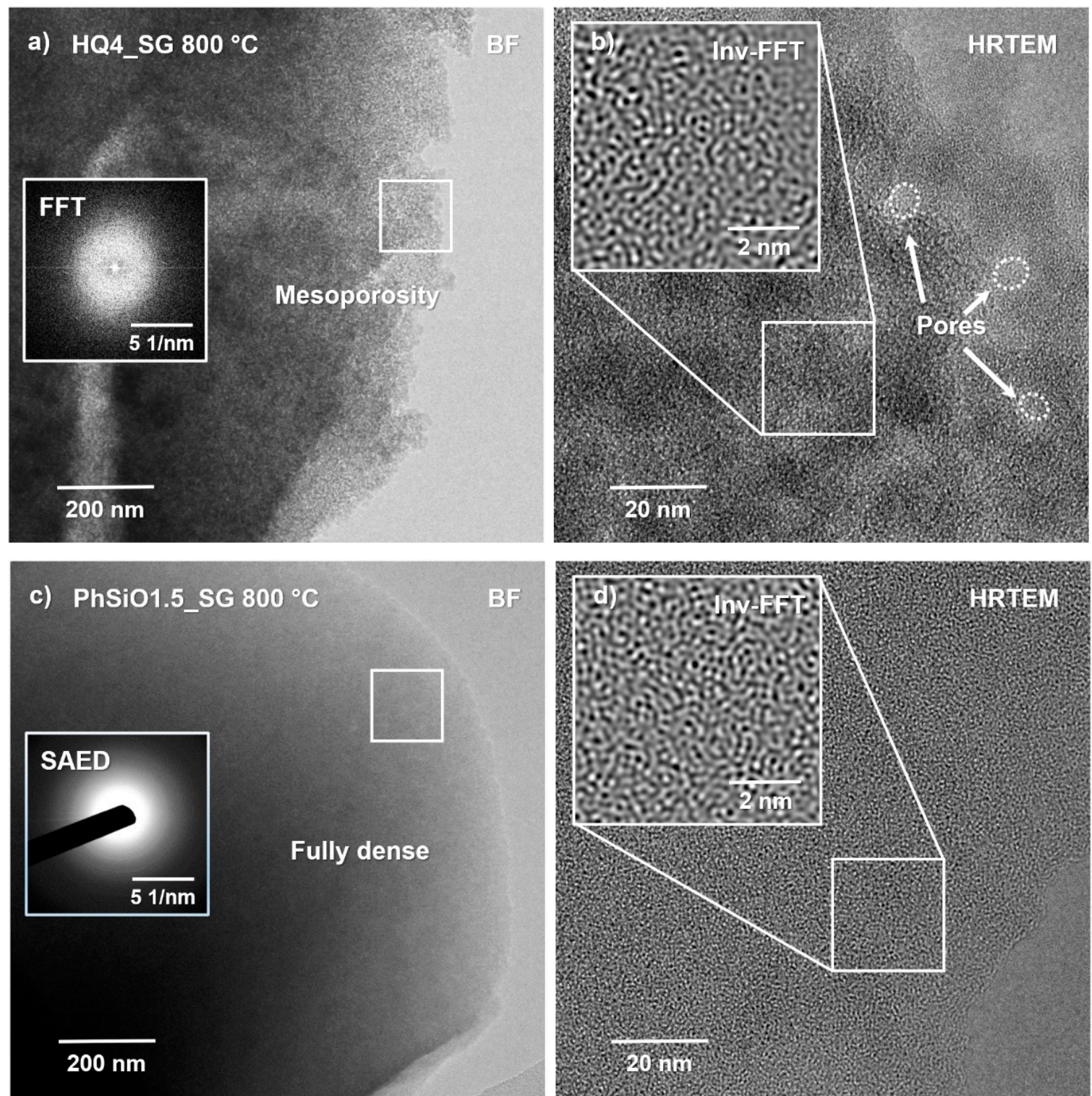

Figure 10. Bright-field (BF) and high-resolution transmission electron microscopy (HRTEM) images of (a,b) the HQ4_SG $800{ }^{\circ} \mathrm{C}$ sample, while in $(\mathbf{c}, \mathbf{d})$ the $\mathrm{PhSiO}_{1.5}$ SG $800{ }^{\circ} \mathrm{C}$ material is depicted. Both samples are fully amorphous, as can be seen from the FFT/SAED insets in $(\mathbf{a}, \mathbf{c})$ as well as from the inverse Fast-Fourier-Transform images (Inv-FFT) given in (b,d). 
One interesting aspect that can be noted when comparing the bright-field (BF) images shown in Figure 10a,b versus Figure 10c,d is that the HQ4_SG $800{ }^{\circ} \mathrm{C}$ sample is highly porous (compare also Figure 11), while the $\mathrm{PhSiO}_{1.5}$ SG $800{ }^{\circ} \mathrm{C}$ material is fully dense without any local porosity or local contrast variation that could be imaged. Even on a $2 \mathrm{~nm}$ scale, as given in the inset in (d), no porosity was detected, while in (b) the observed pore size ranges between $5-10 \mathrm{~nm}$ in diameter. Therefore, the HQ4_SG $800{ }^{\circ} \mathrm{C}$ sample is characterized by a highly mesoporous fully amorphous micro/nanostructure. It is assumed that the small pores are accommodated within a matrix of rounded silica particles being of similar size, ranging approximately between $5-10 \mathrm{~nm}$ in diameter. Considering also the chemical EDS analysis, it is fair to state that this sample is predominantly composed of nanosized silica spheres, with the exception of about $3 \mathrm{wt} . \%$ of the carbon phase (see Table 1). It was expected that the carbon phase is mainly present along the pore walls within the matrix, as reported earlier by Kroll et al. [72] based on density functional theory (DFT) calculations. However, such a lining of the pore walls was not detected, possibly due to (i) the rather low volume fraction of carbon within this sample (as compared to the large intrinsic pore volume) and (ii) that at the low temperature of $800{ }^{\circ} \mathrm{C}$ the carbon phase is assumed to still be rather disordered.
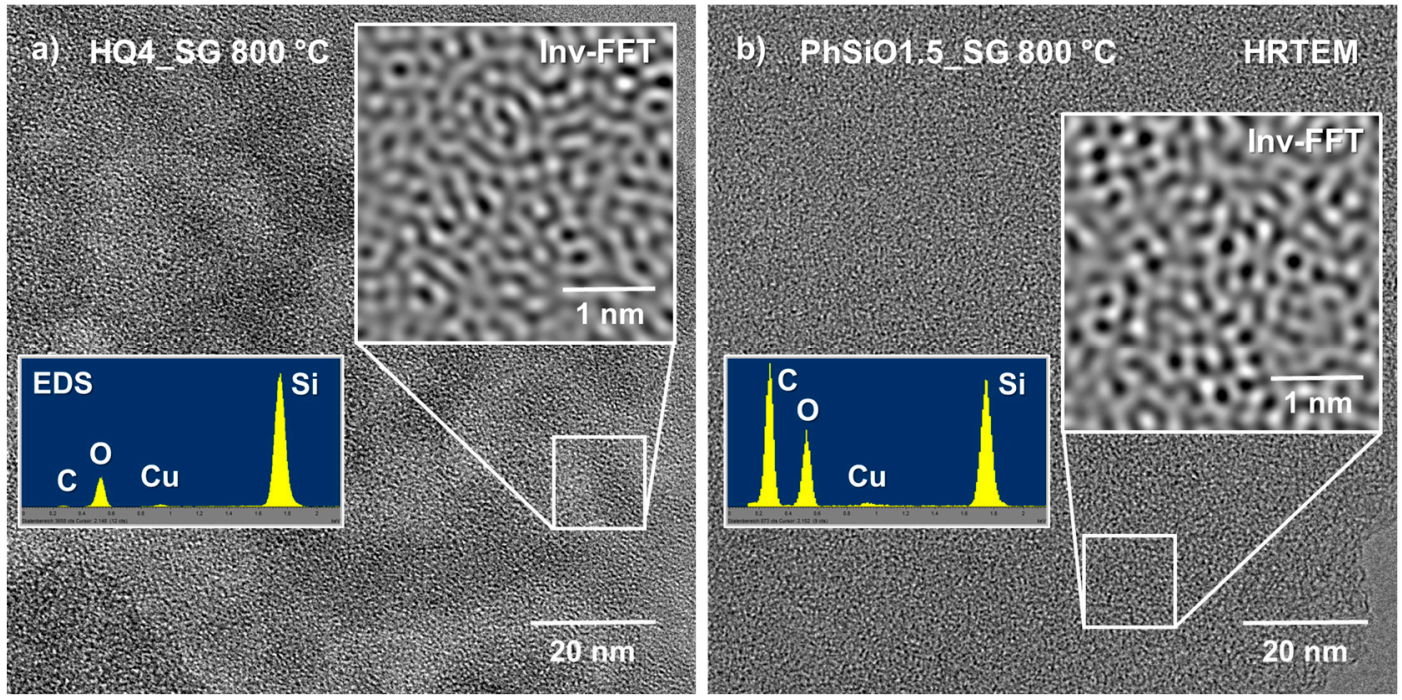

Figure 11. High-resolution transmission electron microscopy images comparing the two materials studied (a) HQ4_SG $800{ }^{\circ} \mathrm{C}$ and (b) $\mathrm{PhSiO}_{1.5}$ SSG $800{ }^{\circ} \mathrm{C}$. The Inv-FFT insets again underline the fully amorphous nature of both samples. However, a major difference found in these samples is the respective chemical composition with a much higher carbon content found in the $\mathrm{PhSiO}_{1.5}$ SG $800{ }^{\circ} \mathrm{C}$ sample (see EDS insets), as compared to the mainly of Si and O composed material HQ4_SG $800^{\circ} \mathrm{C}$. Note that the EDS results are consistent with the chemical analysis reported in Table 1.

The $\mathrm{PhSiO}_{1.5}$ SG $800{ }^{\circ} \mathrm{C}$ sample, on the other hand, contains a comparably high fraction of carbon with ca. $44 \mathrm{wt} . \%$, which however also could not be depicted via HRTEM. One potential reason for not detecting a separate carbon phase would be that the intrinsic polymer network structure is still intact and no phase separation has yet occurred. The rather high content of residual hydrogen of 19 at.\% may be indicative of this assumption. On the other hand, considering that this sample is fully dense and, moreover, that the carbon phase forms a percolation network with an individual structural size of approximately $2-5 \mathrm{~nm}$, the question arises why such a phase was not detectable by HRTEM (with a point resolution of ca. $0.2 \mathrm{~nm}$ )? Here it becomes obvious that, although TEM is commonly considered a very powerful technique, it also has its limitations. Consider a typical TEM sample close to the materials' edge being on the order of $20-50 \mathrm{~nm}$ in thickness and a percolating, disordered phase within the amorphous matrix of only one-tenth of the slab size. Since, unfortunately, we always have to deal with the projection of such microstructural arrangements/features within this sample slab onto the imaging screen, 
this percolation phase will consequently not be visible in the corresponding (projected) image; compare also both Inv-FFT insets in Figure 11. The fact that we are dealing here with more or less disordered structures embedded in a similarly disordered, namely amorphous $\mathrm{SiOC}$ matrix, prevents the detection of the carbon phase.

Lastly, it should be noted that EELS analysis (not shown here) of the low-temperature pyrolysis samples was unfortunately not successful. Both samples reacted rather sensitive under a focused small electron beam and tended to locally decompose during analysis. This is assumed to be a consequence of the rather high residual hydrogen content of ca. 5 versus 20 at.\% in the $\mathrm{HQ} 4 \_\mathrm{SG} 800^{\circ} \mathrm{C}$ and the $\mathrm{PhSiO}{ }_{1.5} \_\mathrm{SG} 800{ }^{\circ} \mathrm{C}$ sample, respectively, whereby local rearrangements of the SiOC network structure and local hydrogen release may have been initiated via the incident electron beam.

\section{Thermochemistry}

High temperature oxidative drop solution calorimetry was used to determine the enthalpy of oxidation and the enthalpies of formation from both elements and components $\left(\mathrm{SiO}_{2}, \mathrm{SiC}, \mathrm{C}, \mathrm{H}_{2} \mathrm{O}\right)$ of the $\mathrm{SiOC}(\mathrm{H})$ PDCs. This method has been well developed and extensively used for the thermodynamic investigation of PDCs $[12-15,21,22,73]$. The calorimetric experiment directly measured the enthalpy of drop solution $\left(\Delta \mathrm{H}_{\mathrm{ds}}\right)$ of the reaction, which can be calculated per mole based on the sample composition. Here one mole of sample is defined as Avogadro's number of atoms $(\mathrm{Si}+\mathrm{O}+\mathrm{C}+\mathrm{H})$, i.e., a gram atom. Due to the high hydrogen content of these samples and the excess oxygen present, relative to that needed to form $\mathrm{SiO}_{2}$, it is assumed that the hydrogen is all bound in water. The high temperature oxidation of the sample occurs as shown in Equation (3).

$$
\begin{gathered}
\mathrm{Si}_{\mathrm{a}} \mathrm{O}_{\mathrm{b}-\mathrm{d} / 2} \mathrm{C}_{\mathrm{c}} \frac{\mathrm{d}}{2} \mathrm{H}_{2} \mathrm{O}\left(\text { solid, } 25^{\circ} \mathrm{C}\right)+\left(\mathrm{a}+\mathrm{c}-\frac{\mathrm{b}}{2}+\frac{\mathrm{d}}{4}\right) \mathrm{O}_{2}\left(\text { gas, } 802{ }^{\circ} \mathrm{C}\right) \rightarrow \\
\text { a } \mathrm{SiO}_{2}\left(\text { cristobalite, } 802{ }^{\circ} \mathrm{C}\right)+\mathrm{c} \mathrm{CO}_{2}\left(\text { gas, } 802{ }^{\circ} \mathrm{C}\right)+\frac{\mathrm{d}}{2} \mathrm{H}_{2} \mathrm{O}\left(\text { gas, } 802{ }^{\circ} \mathrm{C}\right)
\end{gathered}
$$

The enthalpy of oxidation at room temperature and the enthalpy of formation from both elements and components at room temperature were then calculated using thermodynamic cycles shown in Table 5.

All experimental and calculated enthalpies can be found in Table 6. The oxidation at room temperature for all samples is exothermic with $\mathrm{PhSiO}_{1.5} \mathrm{SG}$ samples being more exothermic than HQ4_SG samples. The enthalpy of oxidation is directly related to the amount of carbon present in the PDC. The enthalpy of formation from elements of all samples is exothermic with HQ4_SG samples being more exothermic. Since these values are exothermic, the samples are thermodynamically stable when compared to the elements. The enthalpy of formation from components, $\mathrm{SiO}_{2}$ (cristobalite), $\mathrm{SiC}$, and $\mathrm{C}$ (graphite) for HQ4_SG pyrolyzed at $800{ }^{\circ} \mathrm{C}$ is endothermic with a value of $20.0 \pm 0.9 \mathrm{~kJ} / \mathrm{g} \cdot$ at. This positive enthalpy indicates that HQ4_SG800 is energetically unstable with respect to the crystalline components. The instability may be due to a destabilizing effect caused by the presence of carbon nanoscrolls which may have, as their analogs CNTs, a positive enthalpy of formation from graphite [22,74,75]. The other three samples, HQ4_SG1100, $\mathrm{PhSiO}_{1.5}{ }_{-} \mathrm{SG} 800$ and $\mathrm{PhSiO}_{1.5}$ SG1100 all have negative enthalpies of formation, values ranging from $\sim-3$ to $-14 \mathrm{~kJ} / \mathrm{g}$.at, indicating that they are energetically stable when compared to their crystalline components. The SiOC(H) PDCs with mixed bonding are more energetically stable than their non-mixed bonding counterparts pyrolyzed at the same temperature. While it has been suggested that mixed bonding is the main factor responsible for the thermodynamic stabilities of SiOC PDCs, there must be other factors that contribute to thermodynamic stability, since HQ4_SG1100, with no mixed bonding, is also energetically stable. However, the lack of success in controlling composition makes it impossible to draw definitive conclusions about the relative importance of composition and microstructure. 
Table 5. Thermodynamic cycles for $\operatorname{SiOC}(\mathrm{H})$ heat of formation.

\section{Reaction}

Enthalpy $(\Delta \mathrm{H})$

Enthalpy of oxidation $\left(\Delta \mathrm{H}^{0}{ }_{\text {ox }}\right)$ at $25^{\circ} \mathrm{C}$

(1) $\mathrm{Si}_{\mathrm{a}} \mathrm{O}_{\mathrm{b}-\mathrm{d} / 2} \mathrm{C}_{\mathrm{c}}+\frac{\mathrm{d}}{2} \mathrm{H}_{2} \mathrm{O}\left(\right.$ solid, $\left.25^{\circ} \mathrm{C}\right)+\left(\mathrm{a}+\mathrm{c}-\frac{\mathrm{b}}{2}+\frac{\mathrm{d}}{4}\right) \mathrm{O}_{2}\left(\right.$ gas, $\left.802{ }^{\circ} \mathrm{C}\right) \rightarrow \mathrm{a}$ $\mathrm{SiO}_{2}\left(\right.$ cristobalite, $\left.802{ }^{\circ} \mathrm{C}\right)+\mathrm{c} \mathrm{CO}_{2}\left(\right.$ gas, $\left.802{ }^{\circ} \mathrm{C}\right)+\frac{\mathrm{d}}{2} \mathrm{H}_{2} \mathrm{O}$ (gas, $802{ }^{\circ} \mathrm{C}$ )
(2) $\mathrm{SiO}_{2}$ (cristobalite, $25^{\circ} \mathrm{C}$ ) $\rightarrow \mathrm{SiO}_{2}$ (cristobalite, $802^{\circ} \mathrm{C}$ )
(3) $\mathrm{H}_{2} \mathrm{O}$ (liquid, $\left.25^{\circ} \mathrm{C}\right) \rightarrow \mathrm{H}_{2} \mathrm{O}\left(\right.$ gas, $802{ }^{\circ} \mathrm{C}$ )
$\Delta \mathrm{H}_{2}=50.1 \mathrm{~kJ} / \mathrm{mol}$
(4) $\mathrm{O}_{2}$ (gas, $\left.25^{\circ} \mathrm{C}\right) \rightarrow \mathrm{O}_{2}$ (gas, $802^{\circ} \mathrm{C}$ )
$\Delta \mathrm{H}_{3}=73.1 \mathrm{~kJ} / \mathrm{mol}$
(5) $\mathrm{CO}_{2}$ (gas, $\left.25^{\circ} \mathrm{C}\right) \rightarrow \mathrm{CO}_{2}\left(\right.$ gas, $802{ }^{\circ} \mathrm{C}$ )
$\Delta \mathrm{H}_{4}=25.3 \mathrm{~kJ} / \mathrm{mol}$
$\Delta \mathrm{H}_{5}=37.5 \mathrm{~kJ} / \mathrm{mol}$

$\Delta \mathrm{H}_{1}=\Delta \mathrm{H}_{\mathrm{ds}}(\mathrm{kJ} / \mathrm{g}$ at. $)$

$\mathrm{Si}_{\mathrm{a}} \mathrm{O}_{\mathrm{b}-\mathrm{d} / 2} \mathrm{C}_{\mathrm{c}}+\frac{\mathrm{d}}{2} \mathrm{H}_{2} \mathrm{O}\left(\right.$ solid, $\left.25^{\circ} \mathrm{C}\right)+\left(\mathrm{a}+\mathrm{c}-\frac{\mathrm{b}}{2}+\frac{\mathrm{d}}{4}\right) \mathrm{O}_{2}\left(\right.$ gas, $\left.25^{\circ} \mathrm{C}\right) \rightarrow \mathrm{a}$

$\mathrm{SiO}_{2}\left(\right.$ cristobalite, $\left.25^{\circ} \mathrm{C}\right)+\mathrm{C} \mathrm{CO}_{2}\left(\right.$ gas, $\left.25^{\circ} \mathrm{C}\right)+\frac{\mathrm{d}}{2} \mathrm{H}_{2} \mathrm{O}$ (liquid, $25^{\circ} \mathrm{C}$ )

Enthalpy of formation from the elements $\Delta \mathrm{H}_{\mathrm{f} \text {,elem }}^{0}$ at $25^{\circ} \mathrm{C}$

(1) $\mathrm{Si}_{\mathrm{a}} \mathrm{O}_{\mathrm{b}-\mathrm{d} / 2} \mathrm{C}_{\mathrm{c}}+\frac{\mathrm{d}}{2} \mathrm{H}_{2} \mathrm{O}\left(\right.$ solid, $\left.25^{\circ} \mathrm{C}\right)+\left(\mathrm{a}+\mathrm{c}-\frac{\mathrm{b}}{2}+\frac{\mathrm{d}}{4}\right) \mathrm{O}_{2}\left(\right.$ gas, $\left.25^{\circ} \mathrm{C}\right) \rightarrow \mathrm{a}$ $\mathrm{SiO}_{2}$ (cristobalite, $25^{\circ} \mathrm{C}$ ) $+\mathrm{C} \mathrm{CO}_{2}\left(\right.$ gas, $25^{\circ} \mathrm{C}$ ) $+\frac{\mathrm{d}}{2} \mathrm{H}_{2} \mathrm{O}$ (liquid, $25^{\circ} \mathrm{C}$ )

(2) $\mathrm{Si}$ (solid, $\left.25^{\circ} \mathrm{C}\right)+\mathrm{O}_{2}\left(\right.$ gas, $\left.25^{\circ} \mathrm{C}\right) \rightarrow \mathrm{SiO}_{2}$ (cristobalite, $25^{\circ} \mathrm{C}$ )

$\Delta \mathrm{H}_{2}=-908.4 \pm 2.1 \mathrm{~kJ} / \mathrm{mol}$

(3) $\mathrm{H}_{2}$ (gas, $25^{\circ} \mathrm{C}$ ) $+1 / 2 \mathrm{O}_{2}$ (gas, $\left.25^{\circ} \mathrm{C}\right) \rightarrow \mathrm{H}_{2} \mathrm{O}$ (liquid, $25^{\circ} \mathrm{C}$ )

$\Delta \mathrm{H}_{3}=-285.8 \pm 0.1 \mathrm{~kJ} / \mathrm{mol}$

(4) $\mathrm{C}$ (solid, $\left.25^{\circ} \mathrm{C}\right)+\mathrm{O}_{2}$ (gas, $\left.25^{\circ} \mathrm{C}\right) \rightarrow \mathrm{CO}_{2}$ (gas, $25^{\circ} \mathrm{C}$ )

$\Delta \mathrm{H}_{4}=-393.5 \pm 0.1 \mathrm{~kJ} / \mathrm{mol}$

a Si (solid, $\left.25^{\circ} \mathrm{C}\right)+\frac{\mathrm{b}}{2} \mathrm{O}_{2}\left(\right.$ gas, $25^{\circ} \mathrm{C}+\mathrm{c} \mathrm{C}$ (solid, $\left.25^{\circ} \mathrm{C}\right)+\frac{\mathrm{d}}{2} \mathrm{H}_{2}$ (gas, 25

$\left.{ }^{\circ} \mathrm{C}\right) \rightarrow \mathrm{Si}_{\mathrm{a}} \mathrm{O}_{\mathrm{b}-\mathrm{d} / 2} \mathrm{C}_{\mathrm{c}}+\frac{\mathrm{d}}{2} \mathrm{H}_{2} \mathrm{O}$ (solid, $\left.25^{\circ} \mathrm{C}\right)$

$\Delta \mathrm{H}_{\text {f,elem }}^{0}(\mathrm{~kJ} /$ g-at. $)=-\Delta \mathrm{H}_{1}+\mathrm{a} \Delta \mathrm{H}_{2}+\left(\frac{\mathrm{d}}{2}\right) \Delta \mathrm{H}_{3}$ $+\mathrm{c} \Delta \mathrm{H}_{4}$

Enthalpy of formation from the components $\Delta \mathrm{H}_{\mathrm{f} \text {,comp }}^{0}$ at $25^{\circ} \mathrm{C}$

(1) a Si (solid, $\left.25^{\circ} \mathrm{C}\right)+\frac{\mathrm{b}}{2} \mathrm{O}_{2}\left(\right.$ gas, $\left.25^{\circ} \mathrm{C}\right)+\mathrm{c} \mathrm{C}$ (solid, $\left.25^{\circ} \mathrm{C}\right)+\frac{\mathrm{d}}{2} \mathrm{H}_{2}$ (gas,

$\left.25^{\circ} \mathrm{C}\right) \rightarrow \mathrm{Si}_{\mathrm{a}} \mathrm{O}_{\mathrm{b}-\mathrm{d} / 2} \mathrm{C}_{\mathrm{c}}+\frac{\mathrm{d}}{2} \mathrm{H}_{2} \mathrm{O}$ (solid, $25^{\circ} \mathrm{C}$ )

$\Delta \mathrm{H}_{1}=\Delta \mathrm{H}_{\mathrm{f} \text {,elem }}(\mathrm{kJ} / \mathrm{g} \cdot \mathrm{at}$.

(2) $\mathrm{Si}$ (solid, $\left.25^{\circ} \mathrm{C}\right)+\mathrm{C}\left(\right.$ solid, $\left.25^{\circ} \mathrm{C}\right) \rightarrow \mathrm{SiC}$ (solid, $25^{\circ} \mathrm{C}$ )

$\Delta \mathrm{H}_{2}=-73.2 \pm 6.3 \mathrm{~kJ} / \mathrm{mol}$

(3) $\mathrm{Si}$ (solid, $\left.25^{\circ} \mathrm{C}\right)+\mathrm{O}_{2}$ (gas, $\left.25^{\circ} \mathrm{C}\right) \rightarrow \mathrm{SiO}_{2}$ (cristobalite, $25^{\circ} \mathrm{C}$ )

$\Delta \mathrm{H}_{3}=-908.4 \pm 2.1 \mathrm{~kJ} / \mathrm{mol}$

(4) $\mathrm{H}_{2}$ (gas, $\left.25^{\circ} \mathrm{C}\right)+\mathrm{O}_{2}\left(\right.$ gas, $\left.25^{\circ} \mathrm{C}\right) \rightarrow \mathrm{H}_{2} \mathrm{O}$ (liquid, $25^{\circ} \mathrm{C}$ )

$\Delta \mathrm{H}_{4}=-285.83 \pm 0.04 \mathrm{~kJ} / \mathrm{mol}$

$\left(\mathrm{a}-\frac{\mathrm{b}}{2}+\frac{\mathrm{d}}{4}\right) \mathrm{SiC}\left(\right.$ solid, $\left.25^{\circ} \mathrm{C}\right)+\left(\frac{\mathrm{b}}{2}-\frac{\mathrm{d}}{4}\right) \mathrm{SiO}_{2}$ (cristobalite, $\left.25^{\circ} \mathrm{C}\right)+$

$\left(\mathrm{c}-\mathrm{a}+\frac{\mathrm{b}}{2}-\frac{\mathrm{d}}{4}\right) \mathrm{C}\left(\right.$ solid, $\left.25^{\circ} \mathrm{C}\right)+\frac{\mathrm{d}}{2} \mathrm{H}_{2} \mathrm{O}$ (liquid, $\left.25^{\circ} \mathrm{C}\right) \rightarrow \mathrm{Si}_{\mathrm{a}} \mathrm{O}_{\mathrm{b}-\mathrm{d} / 2} \mathrm{C}_{\mathrm{c}}+\frac{\mathrm{d}}{2}$

$\mathrm{H}_{2} \mathrm{O}$ (solid, $25^{\circ} \mathrm{C}$ )

$\Delta \mathrm{H}_{\mathrm{f}, \mathrm{comp}}(\mathrm{kJ} / \mathrm{g}$-at. $)=\Delta \mathrm{H}_{1}-\left(\mathrm{a}-\frac{\mathrm{b}}{2}+\frac{\mathrm{d}}{4}\right) \Delta \mathrm{H}_{2}$

$-\left(\frac{b}{2}-\frac{d}{4}\right) \Delta \mathrm{H}_{3}-\frac{d}{2} \Delta \mathrm{H}_{4}$

Table 6. Enthalpies of drop solution, enthalpies of oxidation at room temperature, enthalpies of formations from the elements and enthalpies of formation from the components for $\mathrm{SiOC}(\mathrm{H})$ samples.

\begin{tabular}{|c|c|c|c|c|c|c|c|c|}
\hline \multirow{2}{*}{ Sample } & \multicolumn{4}{|c|}{$\mathrm{Si}_{\mathrm{a}} \mathrm{O}_{\mathrm{b}} \mathrm{C}_{\mathrm{c}} \mathrm{H}_{\mathrm{d}}(\mathrm{a}+\mathrm{b}+\mathrm{c}+\mathrm{d}=1)$} & \multirow{2}{*}{$\begin{array}{c}\Delta H_{d s} \\
\text { (kJ/g·at) }\end{array}$} & \multirow{2}{*}{$\begin{array}{c}\Delta H_{o x} \\
(\mathrm{~kJ} / \mathrm{g} \cdot \mathrm{at})\end{array}$} & \multirow{2}{*}{$\begin{array}{c}\Delta H_{f, e l e .} \\
\text { (kJ/g·at) }\end{array}$} & \multirow{2}{*}{$\begin{array}{r}\Delta H_{f, c o m p} \\
(\mathbf{k J} / \mathrm{g} \cdot \mathrm{at})\end{array}$} \\
\hline & $\mathbf{a}$ & $\mathbf{b}$ & c & d & & & & \\
\hline HQ4_SG $800^{\circ} \mathrm{C}$ & 0.286 & 0.619 & 0.047 & 0.048 & $\begin{array}{l}-11.0 \\
\pm 0.2\end{array}$ & $\begin{array}{l}-28.0 \\
\pm 0.2\end{array}$ & $\begin{array}{c}-257.2 \\
\pm 0.6\end{array}$ & $\begin{array}{l}20.0 \\
\pm 0.9\end{array}$ \\
\hline HQ4_SG $1100{ }^{\circ} \mathrm{C}$ & 0.283 & 0.588 & 0.078 & 0.052 & $\begin{array}{c}-12.3 \\
\pm 0.2\end{array}$ & $\begin{array}{c}-29.2 \\
\pm 0.2\end{array}$ & $\begin{array}{c}-265.8 \\
\pm 0.6\end{array}$ & $\begin{array}{l}-3.2 \\
\pm 0.9\end{array}$ \\
\hline $\mathrm{PhSiO}_{1.5}$ _SG $800{ }^{\circ} \mathrm{C}$ & 0.112 & 0.227 & 0.470 & 0.191 & $\begin{array}{c}-203.8 \\
\pm 3.3\end{array}$ & $\begin{array}{c}-221.0 \\
\pm 3.3\end{array}$ & $\begin{array}{c}-93.2 \\
\pm 3.3\end{array}$ & $\begin{array}{l}-2.5 \\
\pm 3.4\end{array}$ \\
\hline $\mathrm{PhSiO}_{1.5 \_\mathrm{SG}} 1100{ }^{\circ} \mathrm{C}$ & 0.142 & 0.230 & 0.568 & 0.060 & $\begin{array}{c}-229.5 \\
\pm 3.9\end{array}$ & $\begin{array}{c}-244.7 \\
\pm 3.9\end{array}$ & $\begin{array}{c}-116.4 \\
\pm 3.9\end{array}$ & $\begin{array}{l}-13.9 \\
\pm 3.9\end{array}$ \\
\hline
\end{tabular}




\section{Conclusions}

The synthesis of two different preceramic polymers with phenyl $\mathrm{R}$ groups, one in which the phenyl group is directly bonded to silicon through $\mathrm{Si}-\mathrm{C}$ bonds and one with the phenyl group bonded to the silicon through Si-O-C bridges, result in SiOC PDCs with significantly different bonding, particularly at the interface between the silica rich nanodomains and the $\mathrm{sp}^{2}$ "free" carbon phase/nanodomains. The synthesis route followed for the $\mathrm{PhSiO}_{1.5} \mathrm{SG}_{\mathrm{S}}$ material, gave direct silicon-carbon bonds in the polymer, resulting in a SiOC PDC with mixed bonding at the interface between the silica-rich and carbonrich regions. The absence of direct $\mathrm{Si}-\mathrm{C}$ bonds in the polymer network generates a $\mathrm{SiOC}$ PDC with no mixed bonding at the interface, as is the case for the HQ4_SG material. These nanodomain bonding patterns are assumed to be relevant for nearly all of the "free" sp ${ }^{2}$ carbon nanodomains in both PDCs, which is confirmed by the presence of radial breathing-like mode bands in the Raman spectra. The specific nature of these curled carbon nanoregions is however not well known and further studies are needed to confirm their morphology. The $2-5 \mathrm{~nm}$ in size mesopores found by TEM in the silica-rich structure of HQ4_SG samples accommodate the spiral-like rolled-up graphene sheets with open $\mathrm{sp}^{3}$ saturated edges. The energetics, as determined by high temperature oxide melt solution calorimetry, confirms that the SiOC PDC materials with mixed bonding are thermodynamically more stable than those without. It became apparent that there are other factors contributing to the thermodynamic stability besides mixed bonding alone in SiOC PDCs, as for example the atomistic structure of the "free" carbon nanodomains.

Author Contributions: Conceptualization, C.S. and G.M.; Data curation, C.S. and S.L.; Formal analysis, C.S. and S.L.; Funding acquisition, A.N.; Project administration, G.M.; Resources, G.M.; Supervision, A.N. and G.M.; Validation, A.N., H.-J.K. and G.M.; Writing-original draft, C.S., S.L. and G.M.; Writing-review \& editing, A.N., H.-J.K. and G.M.. All authors have read and agreed to the published version of the manuscript.

Funding: This research was funded by National Science Foundation Partnerships for International Research and Education (PIRE) award \#1743701 as well as German Science Foundation, DFG grant IO 83/2-1. The APC was funded by MDPI Materials.

Institutional Review Board Statement: Not applicable.

Informed Consent Statement: Not applicable.

Data Availability Statement: The data underlying this article will be shared on reasonable request from the corresponding author.

Acknowledgments: We gratefully acknowledge Sabyasachi Sen, UC Davis, for the continuous support and valuable discussions. We gratefully acknowledge financial support by the National Science Foundation Partnerships for International Research and Education (PIRE) award \#1743701 for Casey Sugie's M.S. thesis involving sample preparation, characterization and calorimetry, as well as for final stages in data analysis and manuscript preparation. GM acknowledges the financial support from the German Science Foundation, DFG grant IO 83/2-1.

Conflicts of Interest: The authors declare no conflict of interest. The funders had no role in the design of the study; in the collection, analyses, or interpretation of data; in the writing of the manuscript, or in the decision to publish the results.

\section{References}

1. Colombo, P.; Mera, G.; Riedel, R.; Sorarù, G.D. Polymer-Derived Ceramics: 40 Years of Research and Innovation in Advanced Ceramics. J. Am. Ceram. Soc. 2010, 93, 1805-1837. [CrossRef]

2. Mera, G.; Riedel, R. Organosilicon-Based Polymers as Precursors for Ceramics. In Polymer Derived Ceramics: From Nano-structure to Applications; Colombo, P., Riedel, R., Soraru, G.D., Kleebe, H.-J., Eds.; DEStech Publications, Inc.: Lancaster, PA, USA, 2009.

3. Riedel, R.; Mera, G.; Hauser, R.; Klonczynski, A. Silicon-Based Polymer-Derived Ceramics: Synthesis Properties and ApplicationsA Review. J. Ceram. Soc. Jpn. 2006, 114, 425-444. [CrossRef]

4. Shah, S.R.; Raj, R. Mechanical Properties of a Fully Dense Polymer Derived Ceramic Made by a Novel Pressure Casting Process. Acta Mater. 2002, 50, 4093-4103. [CrossRef] 
5. Fiocco, L.; Li, S.; Stevens, M.M.; Bernardo, E.; Jones, J.R. Biocompatibility and Bioactivity of Porous Polymer-Derived Ca-Mg Silicate Ceramics. Acta Biomater. 2017, 50, 56-67. [CrossRef]

6. Ionescu, E.; Sen, S.; Mera, G.; Navrotsky, A. Structure, Energetics and Bioactivity of Silicon Oxycarbide-Based Amorphous Ceramics with Highly Connected Networks. J. Eur. Ceram. Soc. 2018, 38, 1311-1319. [CrossRef]

7. Mera, G.; Navrotsky, A.; Sen, S.; Kleebe, H.-J.; Riedel, R. Polymer-Derived SiCN and SiOC Ceramics-Structure and Energetics at the Nanoscale. J. Mater. Chem. A 2013, 1, 3826-3836. [CrossRef]

8. Stabler, C.; Ionescu, E.; Graczyk-Zajac, M.; Gonzalo-Juan, I.; Riedel, R. Silicon Oxycarbide Glasses and Glass-Ceramics: “AllRounder" Materials for Advanced Structural and Functional Applications. J. Am. Ceram. Soc. 2018, 101, 4817-4856. [CrossRef]

9. Pantano, C.G.; Singh, A.K.; Zhang, H. Silicon Oxycarbide Glasses. J. Sol-Gel Sci. Technol. 1999, 14, 7-25. [CrossRef]

10. Mera, G.; Gallei, M.; Bernard, S.; Ionescu, E. Ceramic Nanocomposites from Tailor-Made Preceramic Polymers. Nanomaterials 2015, 5, 468-540. [CrossRef]

11. Widgeon, S.J.; Sen, S.; Mera, G.; Ionescu, E.; Riedel, R.; Navrotsky, A. 29Si and 13C Solid-State NMR Spectroscopic Study of Nanometer-Scale Structure and Mass Fractal Characteristics of Amorphous Polymer Derived Silicon Oxycarbide Ceramics. Chem. Mater. 2010, 22, 6221-6228. [CrossRef]

12. Morcos, R.M.; Mera, G.; Navrotsky, A.; Varga, T.; Riedel, R.; Poli, F.; Müller, K. Enthalpy of Formation of Carbon-Rich PolymerDerived Amorphous SiCN Ceramics. J. Am. Ceram. Soc. 2008, 91, 3349-3354. [CrossRef]

13. Niu, M.; Wang, H.; Chen, J.; Su, L.; Wu, D.; Navrotsky, A. Structure and Energetics of SiOC and SiOC-Modified Carbon-Bonded Carbon Fiber Composites. J. Am. Ceram. Soc. 2017, 100, 3693-3702. [CrossRef]

14. Tavakoli, A.H.; Campostrini, R.; Gervais, C.; Babonneau, F.; Bill, J.; Sorarù, G.D.; Navrotsky, A. Energetics and Structure of Polymer-Derived Si-(B-)O-C Glasses: Effect of the Boron Content and Pyrolysis Temperature. J. Am. Ceram. Soc. 2014, 97, 303-309. [CrossRef]

15. Varga, T.; Navrotsky, A.; Moats, J.L.; Morcos, R.M.; Poli, F.; Müller, K.; Saha, A.; Raj, R. Thermodynamically Stable SixOyCz Polymer-Like Amorphous Ceramics. J. Am. Ceram. Soc. 2007, 90, 3213-3219. [CrossRef]

16. Widgeon, S.; Mera, G.; Gao, Y.; Stoyanov, E.; Sen, S.; Navrotsky, A.; Riedel, R. Nanostructure and Energetics of Carbon-Rich SiCN Ceramics Derived from Polysilylcarbodiimides: Role of the Nanodomain Interfaces. Chem. Mater. 2012, 24, 1181-1191. [CrossRef]

17. Navrotsky, A. Thermochemical Studies of Nitrides and Oxynitrides by Oxidative Oxide Melt Calorimetry. J. Alloys Compd. 2001, 321, 300-306. [CrossRef]

18. Navrotsky, A. Progress and New Directions in High Temperature Calorimetry Revisited. Phys. Chem. Miner. 1997, 24, 222-241. [CrossRef]

19. McHale, J.M.; Navrotsky, A.; Kowach, G.R.; Disalvo, F.J. Thermochemistry of Metal Nitrides in the Ca/Zn/N System. Chem. A Eur. J. 1996, 2, 1514-1517. [CrossRef]

20. Navrotsky, A. Progress and New Directions in High Temperature Calorimetry. Phys. Chem. Miner. 1977, 2, 89-104. [CrossRef]

21. Morcos, R.M.; Navrotsky, A.; Varga, T.; Blum, Y.; Ahn, D.; Poli, F.; Müller, K.; Raj, R. Energetics of SixOyCz Polymer-Derived Ceramics Prepared Under Varying Conditions. J. Am. Ceram. Soc. 2008, 91, 2969-2974. [CrossRef]

22. Mera, G.; Kroll, P.; Ponomarev, I.; Chen, J.; Morita, K.; Liesegang, M.; Ionescu, E.; Navrotsky, A. Metal-Catalyst-Free Access to Multiwalled Carbon Nanotubes/Silica Nanocomposites (MWCNT/SiO 2 ) from a Single-Source Precursor. Dalt. Trans. 2019, 48, 11018-11033. [CrossRef] [PubMed]

23. Narisawa, M.; Funabiki, F.; Iwase, A.; Wakai, F.; Hosono, H. Effects of Atmospheric Composition on the Molecular Structure of Synthesized Silicon Oxycarbides. J. Am. Ceram. Soc. 2015, 98, 3373-3380. [CrossRef]

24. Graczyk-Zajac, M.; Vrankovic, D.; Waleska, P.; Hess, C.; Sasikumar, P.V.; Lauterbach, S.; Kleebe, H.-J.; Sorarù, G.D. The Li-Storage Capacity of SiOC Glasses with and without Mixed Silicon Oxycarbide Bonds. J. Mater. Chem. A 2018, 6, 93-103. [CrossRef]

25. Ionescu, E.; Linck, C.; Fasel, C.; Müller, M.; Kleebe, H.; Riedel, R. Polymer-Derived SiOC $/ \mathrm{ZrO}_{2}$ Ceramic Nanocomposites with Excellent High-Temperature Stability. J. Am. Ceram. Soc. 2010, 93, 241-250. [CrossRef]

26. Navrotsky, A. Progress and New Directions in Calorimetry: A 2014 Perspective. J. Am. Ceram. Soc. 2014, 97, 3349-3359. [CrossRef]

27. Chen, J.; King, S.W.; Muthuswamy, E.; Koryttseva, A.; Wu, D.; Navrotsky, A. Thermodynamic Stability of Low-k Amorphous SiOCH Dielectric Films. J. Am. Ceram. Soc. 2016, 99, 2752-2759. [CrossRef]

28. Lee, D.W.; Kawakami, Y. Incompletely Condensed Silsesquioxanes: Formation and Reactivity. Polym. J. 2007, 39, 230-238. [CrossRef]

29. Morimoto, S.; Imoto, H.; Naka, K. POSS Solid Solutions Exhibiting Orientationally Disordered Phase Transitions. Chem. Commun. 2017, 53, 9273-9276. [CrossRef]

30. Zemnukhova, L.; Panasenko, A.; Artem'yanov, A.; Tsoy, E. Dependence of Porosity of Amorphous Silicon Dioxide Prepared from Rice Straw on Plant Variety. BioResources 2015, 10, 3713-3723. [CrossRef]

31. Pandurangi, R.S.; Seehra, M.S.; Razzaboni, B.L.; Bolsaitis, P. Surface and Bulk Infrared Modes of Crystalline and Amorphous Silica Particles: A Study of the Relation of Surface Structure to Cytotoxicity of Respirable Silica. Environ. Health Perspect. 1990, 86, 327-336. [CrossRef]

32. Morrow, B.A.; McFarlan, A.J. Surface Vibrational Modes of Silanol Groups on Silica. J. Phys. Chem. 1992, 96, 1395-1400. [CrossRef]

33. Jeleń, P.; Szumera, M.; Gawęda, M.; Długoń, E.; Sitarz, M. Thermal Evolution of Ladder-like Silsesquioxanes during Formation of Black Glasses. J. Therm. Anal. Calorim. 2017, 130, 103-111. [CrossRef] 
34. Jeleń, P.; Bik, M.; Nocuń, M.; Gawęda, M.; Długoń, E.; Sitarz, M. Free Carbon Phase in SiOC Glasses Derived from Ladder-like Silsesquioxanes. J. Mol. Struct. 2016, 1126, 172-176. [CrossRef]

35. Lee, K.-M.; Chang, Y.; Chi, K.; Navamathavan, R. Characteristics of SiOC(-H) Thin Films Prepared by Using Plasma-Enhanced Atomic Layer Deposition. J. Korean Phys. Soc. 2011, 59, 3074-3079. [CrossRef]

36. Sitarz, M. The Structure of Simple Silicate Glasses in the Light of Middle Infrared Spectroscopy Studies. J. Non-Cryst. Solids 2011, 357, 1603-1608. [CrossRef]

37. Niemiec, W.; Szczygieł, P.; Jeleń, P.; Handke, M. IR Investigation on Silicon Oxycarbide Structure Obtained from Precursors with 1:1 Silicon to Carbon Atoms Ratio and Various Carbon Atoms Distribution. J. Mol. Struct. 2018, 1164, 217-226. [CrossRef]

38. Chen, Q.; Xue, F.; Ding, E. Preparation of POSS-Triol/Wollastonite Composite Particles by Liquid Phase Mechanochemical Method and Its Application in UV Curable Coatings. Sci. Eng. Compos. Mater. 2019, 26, 183-196. [CrossRef]

39. Penso, I.; Cechinatto, E.A.; Machado, G.; Luvison, C.; Wanke, C.H.; Bianchi, O.; Soares, M.R.F. Preparation and Characterization of Polyhedral Oligomeric Silsesquioxane (POSS) Using Domestic Microwave Oven. J. Non-Cryst. Solids 2015, 428, 82-89. [CrossRef]

40. Sitarz, M.; Jastrzębski, W.; Jeleń, P.; Długoń, E.; Gawęda, M. Preparation and Structural Studies of Black Glasses Based on Ladder-like Silsesquioxanes. Spectrochim. Acta Part A Mol. Biomol. Spectrosc. 2014, 132, 884-888. [CrossRef] [PubMed]

41. Handke, M.; Handke, B.; Kowalewska, A.; Jastrzębski, W. New Polysilsesquioxane Materials of Ladder-like Structure. J. Mol. Struct. 2009, 924-926, 254-263. [CrossRef]

42. Segatelli, M.G.; Pires, A.T.N.; Yoshida, I.V.P. Synthesis and Structural Characterization of Carbon-Rich SiCxOy Derived from a Ni-Containing Hybrid Polymer. J. Eur. Ceram. Soc. 2008, 28, 2247-2257. [CrossRef]

43. Handke, M.; Jastrzębski, W.; Kowalewska, A.; Mozgawa, W. Spectroscopic Study of Preceramic Polymers (Xerogels) Obtained by Hydrolytic Condensation of Ethoxycyclosiloxanes. J. Mol. Struct. 2009, 924-926, 248-253. [CrossRef]

44. Grill, A.; Neumayer, D.A. Structure of Low Dielectric Constant to Extreme Low Dielectric Constant SiCOH Films: Fourier Transform Infrared Spectroscopy Characterization. J. Appl. Phys. 2003, 94, 6697-6707. [CrossRef]

45. Hair, M.L. Hydroxyl Groups on Silica Surface. J. Non-Cryst. Solids 1975, 19, 299-309. [CrossRef]

46. Davydov, V.Y.; Kiselev, A.V.; Zhuravlev, L.T. Study of the Surface and Bulk Hydroxyl Groups of Silica by Infra-Red Spectra and D2O-Exchange. Trans. Faraday Soc. 1964, 60, 2254-2264. [CrossRef]

47. Zhuravlev, L.T. Concentration of Hydroxyl Groups on the Surface of Amorphous Silicas. Langmuir 1987, 3, 316-318. [CrossRef]

48. Sen, S.; Widgeon, S.J.; Navrotsky, A.; Mera, G.; Tavakoli, A.; Ionescu, E.; Riedel, R. Carbon Substitution for Oxygen in Silicates in Planetary Interiors. Proc. Natl. Acad. Sci. USA 2013, 110, 15904-15907. [CrossRef]

49. Liang, T.; Li, Y.-L.; Su, D.; Du, H.-B. Silicon Oxycarbide Ceramics with Reduced Carbon by Pyrolysis of Polysiloxanes in Water Vapor. J. Eur. Ceram. Soc. 2010, 30, 2677-2682. [CrossRef]

50. Léonardelli, S.; Facchini, L.; Fretigny, C.; Tougne, P.; Legrand, A.P. Silicon-29 Nuclear Magnetic Resonance Study of Silica. J. Am. Chem. Soc. 1992. [CrossRef]

51. Sindorf, D.W.; Maciel, G.E. Silicon-29 Nuclear Magnetic Resonance Study of Hydroxyl Sites on Dehydrated Silica Gel Surfaces, Using Silylation as a Probe. J. Phys. Chem. 1983, 87, 5516-5521. [CrossRef]

52. Luhmer, M.; d'Espinose, J.B.; Hommel, H.; Legrand, A.P. High-Resolution 29Si Solid-State NMR Study of Silicon Functionality Distribution on the Surface of Silicas. Magn. Reson. Imaging 1996, 14, 911-913. [CrossRef]

53. Walther, K.L.; Wokaun, A.; Baiker, A. Characterization of Porous Silica Gels Prepared via the Sol-Gel Process by 29Si CP/MAS Solid-State NMR Spectroscopy. Mol. Phys. 1990, 71, 769-780. [CrossRef]

54. Freitas, J.C.C.; Cipriano, D.F.; Zucolotto, C.G.; Cunha, A.G.; Emmerich, F.G. Solid-State ${ }^{13}$ C NMR Spectroscopy Applied to the Study of Carbon Blacks and Carbon Deposits Obtained by Plasma Pyrolysis of Natural Gas. J. Spectrosc. 2016, 2016, 1543273. [CrossRef]

55. Freitas, J.; Cunha, A.; Emmerich, F. Solid-State Nuclear Magnetic Resonance (NMR) Methods Applied to the Study of Carbon Materials. In Chemistry \& Physics of Carbon. Series: Chemistry and Physics of Carbon; Ljubisa, R., Ed.; CRC Press: Boca Raton, FL, USA, 2012; pp. 85-170. ISBN 978-1-4398-2094-0. [CrossRef]

56. Ruz, P.; Banerjee, S.; Pandey, M.; Sudarsan, V.; Sastry, P.U.; Kshirsagar, R.J. Structural Evolution of Turbostratic Carbon: Implications in H2 Storage. Solid State Sci. 2016, 62, 105-111. [CrossRef]

57. De Souza, F.A.L.; Ambrozio, A.R.; Souza, E.S.; Cipriano, D.F.; Scopel, W.L.; Freitas, J.C.C. NMR Spectral Parameters in Graphene, Graphite, and Related Materials: Ab Initio Calculations and Experimental Results. J. Phys. Chem. C 2016, 120, $27707-27716$. [CrossRef]

58. Dybowski, C.; Gaffney, E.J.; Sayir, A.; Rabinowitz, M.J. Solid-State 13C and 29Si MAS NMR Spectroscopy of Silicon Carbide. Colloids Surfaces A Physicochem. Eng. Asp. 1996, 118, 171-181. [CrossRef]

59. Kitaygorodskiy, A.; Wang, W.; Xie, S.-Y.; Lin, Y.; Shiral Fernando, K.A.; Wang, X.; Qu, L.; Chen, B.; Sun, Y.-P. NMR Detection of Single-Walled Carbon Nanotubes in Solution. J. Am. Chem. Soc. 2005, 127, 7517-7520. [CrossRef]

60. Goze-Bac, C.; Latil, S.; Lauginie, P.; Jourdain, V.; Conard, J.; Duclaux, L.; Rubio, A.; Bernier, P. Magnetic Interactions in Carbon Nanostructures. Carbon N. Y. 2002, 40, 1825-1842. [CrossRef]

61. Latil, S.; Henrard, L.; Bac, C.G.; Bernier, P.; Rubio, A. NMR Chemical Shift of Single-Wall Carbon Nanotubes. Phys. Rev. Lett. 2001, 86, 3160-3163. [CrossRef]

62. Zurek, E.; Autschbach, J. Density Functional Calculations of the 13C NMR Chemical Shifts in $(9,0)$ Single-Walled Carbon Nanotubes. J. Am. Chem. Soc. 2004, 126, 13079-13088. [CrossRef] 
63. Marques, M.A.L.; d'Avezac, M.; Mauri, F. Magnetic Response and NMR Spectra of Carbon Nanotubes from Ab Initio Calculations. Phys. Rev. B 2006, 73, 125433. [CrossRef]

64. Abou-Hamad, E.; Kim, Y.; Talyzin, A.V.; Goze-Bac, C.; Luzzi, D.E.; Rubio, A.; Wågberg, T. Hydrogenation of C60 in Peapods: Physical Chemistry in Nano Vessels. J. Phys. Chem. C 2009, 113, 8583-8587. [CrossRef]

65. Abou-Hamad, E.; Babaa, M.-R.; Bouhrara, M.; Kim, Y.; Saih, Y.; Dennler, S.; Mauri, F.; Basset, J.-M.; Goze-Bac, C.; Wågberg, T. Structural Properties of Carbon Nanotubes Derived from NMR. Phys. Rev. B 2011, 84, 165417. [CrossRef]

66. Hodkiewicz, J.; Scientific, T.F. Characterizing Carbon Materials with Raman Spectroscopy. Prog. Mater. Sci. 2005, 17, 10. [CrossRef]

67. Lei, X.-W.; Ni, Q.-Q.; Shi, J.-X.; Natsuki, T. Radial Breathing Mode of Carbon Nanotubes Subjected to Axial Pressure. Nanoscale Res. Lett. 2011, 6, 492. [CrossRef]

68. Batra, R.C.; Gupta, S.S. Wall Thickness and Radial Breathing Modes of Single-Walled Carbon Nanotubes. J. Appl. Mech. 2008, 75. [CrossRef]

69. Maultzsch, J.; Telg, H.; Reich, S.; Thomsen, C. Radial Breathing Mode of Single-Walled Carbon Nanotubes: Optical Transition Energies and Chiral-Index Assignment. Phys. Rev. B Condens. Matter Mater. Phys. 2005, 72, 205438. [CrossRef]

70. Canado, L.G.; Takai, K.; Enoki, T.; Endo, M.; Kim, Y.A.; Mizusaki, H.; Jorio, A.; Coelho, L.N.; Magalhães-Paniago, R.; Pimenta, M.A. General Equation for the Determination of the Crystallite Size La of Nanographite by Raman Spectroscopy. Appl. Phys. Lett. 2006, 88, 163106. [CrossRef]

71. Cançado, L.G.; Jorio, A.; Ferreira, E.H.M.; Stavale, F.; Achete, C.A.; Capaz, R.B.; Moutinho, M.V.O.; Lombardo, A.; Kulmala, T.S.; Ferrari, A.C. Quantifying Defects in Graphene via Raman Spectroscopy at Different Excitation Energies. Nano Lett. 2011, 11, 3190-3196. [CrossRef] [PubMed]

72. Kroll, P. Modeling the 'Free Carbon' Phase in Amorphous Silicon Oxycarbide. J. Non-Cryst. Solids 2005, 351, 1121-1126. [CrossRef]

73. Tavakoli, A.H.; Armentrout, M.M.; Sen, S.; Navrotsky, A. Hydrogenated Si-O-C Nanoparticles: Synthesis, Structure, and Thermodynamic Stability. J. Mater. Res. 2015, 30, 295-303. [CrossRef]

74. Cherkasov, N.B.; Savilov, S.V.; Ivanov, A.S.; Lunin, V.V. Bomb Calorimetry as a Bulk Characterization Tool for Carbon Nanostructures. Carbon N. Y. 2013, 63, 324-329. [CrossRef]

75. Levchenko, A.A.; Kolesnikov, A.I.; Trofymluk, O.; Navrotsky, A. Energetics of Single-Wall Carbon Nanotubes as Revealed by Calorimetry and Neutron Scattering. Carbon N. Y. 2011, 49, 949-954. [CrossRef] 